\title{
Solving the pan evaporation process complexity using the development of multiple mode of neurocomputing models
}

\section{Mohammad Ali Ghorbani}

University of Tabriz Faculty of Agriculture

Milad Alizadeh Jabehdar ( $\triangle$ mAlizadehj97@gmail.com )

University of Tabriz Faculty of Agriculture https://orcid.org/0000-0003-4059-6753

\section{Zaher Mundher Yaseen}

Duy Tan University

Samed Inyurt

Tokat Gaziosmanpaşa University

\section{Research Article}

Keywords: Artificial intelligence, Neural networks, Pan evaporation, Prediction, Multiple model strategy, Support vector machine.

Posted Date: February 25th, 2021

DOl: https://doi.org/10.21203/rs.3.rs-157647/v1

License: (9) This work is licensed under a Creative Commons Attribution 4.0 International License. Read Full License

Version of Record: A version of this preprint was published at Theoretical and Applied Climatology on July 13th, 2021. See the published version at https://doi.org/10.1007/s00704-021-03724-8. 


\section{Solving the pan evaporation process complexity using the development of multiple mode of neurocomputing models}

Mohammad Ali Ghorbani ${ }^{1,2}$, Milad Alizadeh Jabehdar ${ }^{*}$, Zaher Mundher Yaseen ${ }^{3}$, Samed Inyurt ${ }^{4}$

${ }^{1}$ Department of Water Engineering, Faculty of Agriculture, University of Tabriz, Tabriz, Iran. E-mail: Ghorbani@tabrizu.ac.ir

${ }^{2}$ Istanbul Technical University, Department of Civil Engineering, Istanbul, Turkey

${ }^{1}$ Department of Water Engineering, Faculty of Agriculture, University of Tabriz, Tabriz, Iran.

*Corresponding Author E-mail address: malizadehj97@gmail.com Telephone number: +989211460997

${ }^{3}$ Institute of Research and Development, Duy Tan University, Da Nang, 550000, Vietnam. E-mail: zahermundheryaseen@duytan.edu.vn

${ }^{4}$ Department of Geomatics Engineering, Faculty of Engineering, Tokat Gaziosmanpaşa University, Tokat, Turkey.

E-mail: Samed_inyurt@hotmail.com

Corresponding Author: Milad Alizadeh Jabehdar 


\begin{abstract}
Finding an accurate computational method for predicting pan evaporation $(E P)$, can be useful in the application of these methods for the development of sustainable agricultural systems and water resources management. In the present study, the proposed hybrid method called Multiple ModelSupport Vector Machine (MM-SVM) with the aim of increasing the accuracy of EP prediction on a monthly scale $\left(E P_{m}\right)$ in two meteorological stations (Ardabil and Khalkhal) using the output of artificial intelligence (AI) models (i.e., artificial neural network (ANN) and support vector machine (SVM)) were evaluated. The results of intelligent models using several statistical indices (i.e., root mean square error (RMSE), mean absolute error value (MAE), Kling-Gupta (KGE) and coefficient of determination $\left(\mathrm{R}^{2}\right)$ ) and with the help of case visual indicators Were compared. According to the results of evaluation indicators in the test phase, two models MM-SVM-6 and ANN-5 with (RMSE, MAE, KGE and $\mathrm{R}^{2}$ equal to $1.088,0.761,0.79,0.54 \mathrm{~mm}$. month $^{-1}, 0.819$, 0.903 and $0.939,0.962$ ) and with three input variables, were introduced as the top models in Ardabil and Khalkhal stations, respectively. The proposed hybrid model (MM-SVM) was able to use its multi-model strategy with inputs predicted by independent models, its power to predict $E P_{m}$ in scenarios where there is a high correlation between its components with $E P_{m}$, in a feasible state Accept to show. So that the incremental, constant and decreasing modes in $E P_{m}$ prediction accuracy by this hybrid model under the above conditions (especially in Ardabil station) were quite clear. Therefore, the results of the proposed and superior models in the present study can help local stakeholders in discussing water resources management.
\end{abstract}

Keywords: Artificial intelligence, Neural networks, Pan evaporation, Prediction, Multiple model strategy, Support vector machine.

\title{
1. Introduction
}

Evaporation is known as an important hydrological process that converts liquid water to steam, and this factor, along with evapotranspiration, leads to the loss of $60 \%$ of global rainfall (Ghaemi et al. 2019; Kisi 2015; Malik et al. 2020b). Despite this, evaporation is less well known as a component of the hydrological cycle (Jing et al. 2019). Therefore, it is important to accurately predict the rate of evaporation, especially in arid and semi-arid regions, which has a critical impact on agricultural issues and water resources management (Ashrafzadeh et al. 2020; Ghorbani et al. 2018a). Evaporation is important in arid and semi-arid regions because the level of evaporation is higher compared to other elements of the hydrological cycle such as precipitation and groundwater flow. Evaporation rate mainly depends on meteorological factors such as air temperature, wind 
speed, relative humidity and vapor pressure (Yaseen et al. 2020). Evaporation can be measured using two methods: direct and indirect methods. Pan evaporation $\left(E_{p}\right)$ is known as one of the direct measurement methods (Eslamian et al. 2008; Kisi et al. 2016). Class A -type Pan evaporation (US Weather Bureau) with $4 \mathrm{ft}(122 \mathrm{~cm})$ in diameter and 10 inch $(25 \mathrm{~cm})$ deep and is located about 6 inch $(15 \mathrm{~cm})$ above the soil surface, are used worldwide to measure free-surface evaporation as well as to estimate reference evapotranspiration (ETo) (Khosravi et al. 2019; Rahimikhoob 2009). Although Pan evaporation is very useful in measuring direct evaporation, it faces limitations such as the number of stations where Pan evaporation is located, the high cost of setting up and installing safety tools, and its maintenance in research projects. In addition, it is difficult to derive a precise formula for all physical evaporation processes due to its instability, nonlinearity, and complexity. To overcome these difficulties, many researchers in recent years have tried to use indirect methods to predict $E_{p}$ using meteorological parameters. Indirect methods include the use of artificial intelligence (AI) algorithms such as artificial neural networks (ANNs) and support vector machines (SVMs), which have been widely used by researchers to extract the relationship between meteorological and $\mathrm{E}_{\mathrm{p}}$ data (Bruton et al. 2000; Ghorbani et al. 2013; Kişi 2006; Malik et al. 2020a; Seifi and Soroush 2020). The development of ANN and SVM intelligent models in a study aimed at estimating monthly Pan evaporation, conducted by (Eslamian et al. 2008). The results of their research showed the high ability of ANN and SVM models in estimating $E_{p}$ and in general, the SVM method was superior to the ANN method. In order to estimate Pan evaporation in a hot and dry area (Piri et al. 2009). the authors conducted ANN model and integrated model based on ANN and autoregression with exogenous inputs. The results indicate the high ability of integrated model ANN compared to single model ANN. Was. Also, the above two models showed better results than two empirical methods. In a research (Ghorbani et al. 2018a), scholars used a hybrid prediction model (Multilayer Perceptron-Firefly Algorithm (MLP-FFA)) based on the FFA optimizer embedded in the MLP method to predict Pan evaporation and the results of the MLPFFA hybrid model. Compared with traditional MLP and SVM models. The results of their research showed that the optimal MLP-FFA model performs better in estimating EP than the MLP and SVM models, and this shows the importance of the firefly algorithm in improving the performance of the MLP-FFA model. The examination of tree classification and regression (C\&RT) methods, automatic chi-square interaction tracker (CHAID), and ANN to predict daily EP in arid regions (Kisi et al. 2016). In a study using multilayer perceptron method with error backpropagation learning algorithm to estimate daily $E P$ and finally found that ANN method is better than Stephens and Stewart models (Sudheer et al. 2002). In another study, researchers estimated the daily $E P$ in the semi-arid region of Iran, two methods of artificial neural network (ANN) and multivariate nonlinear regression (MNLR) were examined by determining the different combinations of climatic variables (Tabari et al. 2010). Their research results showed higher accuracy of ANN model compared to MNLR. An evaluation for the capability of three models including ANN, Active Fuzzy Neural Inference System (CANFIS) and Multiple Linear Regression (MLR) with the aim of predicting pan evaporation at a number of Indian stations (Malik et al. 2019). The results of their research showed the high accuracy of the ANN model compared to CANFIS and MLR. 
Another researcher conducted a study to evaluate the accuracy of least square support vector machine (LSSVM), multivariate adaptive regression splines (MARS) and M5 model tree (M5Tree) in estimating EP (Kisi 2015). The results of their research showed that the LSSVM model was superior to other models in cases where station inputs and outputs were considered.

In the present study, several input combinations (scenarios) to evaluate the Multiple ModelSupport Vector Machine (MM-SVM) with the aim of improving the results of predicting $E P_{m}$ compared to the two models ANN and SVM and also to determine the behavioral pattern of the combined MM-SVM model Used. In general, the strategy of multiple models has shown great potential in various discussions of hydrological engineering. Among the efficiency of multiple models are the ability of these models to predict and detect river flow, pan evaporation, cation exchange capacity and hydraulic conductivity of saturated soil (Ghorbani et al. 2018b; Kashani et al. 2020; Khatibi et al. 2018; Khatibi et al. 2017). In this research, the strategy of multiple models is presented by presenting a new perspective to improve the prediction of the evaporation process from the pan due to its randomness and nonlinearity.

\section{Materials and method}

\subsection{Study region and datasets}

Ardabil province with an area of 17867.3 square kilometers (1.1 percent of the area of Iran) is located in the northwest of the Iranian plateau between 37.75 to 39.70 degrees north latitude and 47.50 to 48.92 degrees east longitude. Its average altitude is 2400 meters above sea level. Its lowest elevation point with a height of 100 meters is in the cities of Parsabad and BilehSavar and its highest point is Mount Sabalan with a height of 4811 meters. In the present study, among 9 synoptic stations located in Ardabil province, the data of Ardabil and Khalkhal meteorological stations, which have a more complete statistical period and are also located in two different points of the province, were used on a monthly time scale. Data on average temperature $\left({ }^{\circ} \mathrm{C}\right)$, relative humidity $(\%)$, average wind speed $\left(\mathrm{m} . ~^{-1}\right)$, total hours of sunshine (hours) and average pan evaporation (mm/month) for the statistical period 2009-2019 (11 years) was obtained from Ardabil Meteorological Organization. The approximate position of Ardabil and Khalkhal synoptic stations is shown in Fig. 1. Table 1, shows the statistical characteristics related to the data of the parameters used in the two stations. Data from 2009 to 2016 (i.e., $73 \%$ or 96 months) for the training period and 2017 to 2019 (i.e., $27 \%$ or 32 months) for the test period (validation) were used. Fig. 2 shows the time series of monthly changes of evaporation from the pan at Ardabil and Khalkhal stations in the study period 2009-2019. Also, the boxplot of the normalized input and output parameters $\left(E P_{m}\right)$ of the two stations of Ardabil and Khalkhal is shown in Fig. 3. All modeling steps were

performed in WEKA software version 3.9.4, developed by Waikato University in New Zealand (Garner 1995). 


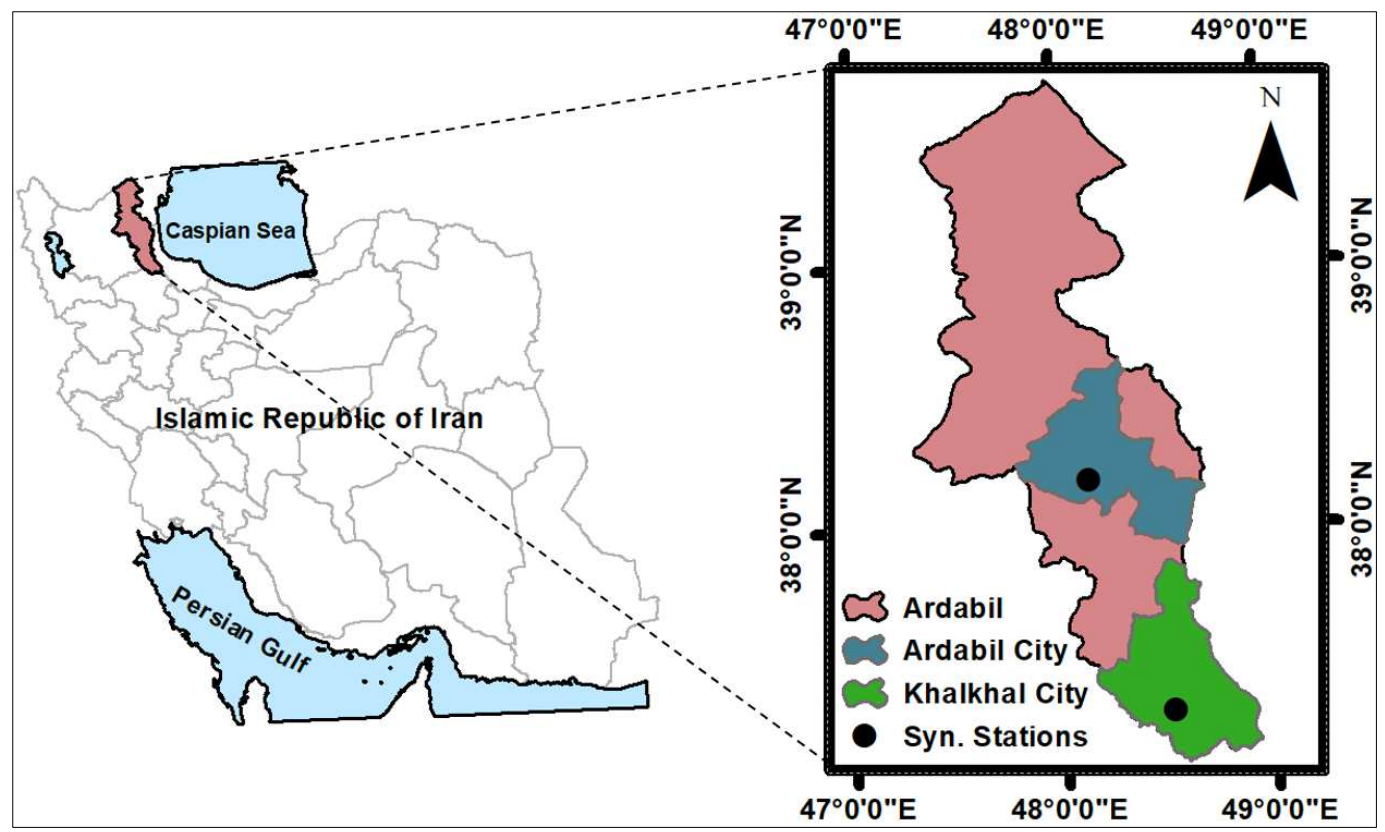

Fig. 1. Geographic location of the Ardabil and Khalkhal meteorological stations.
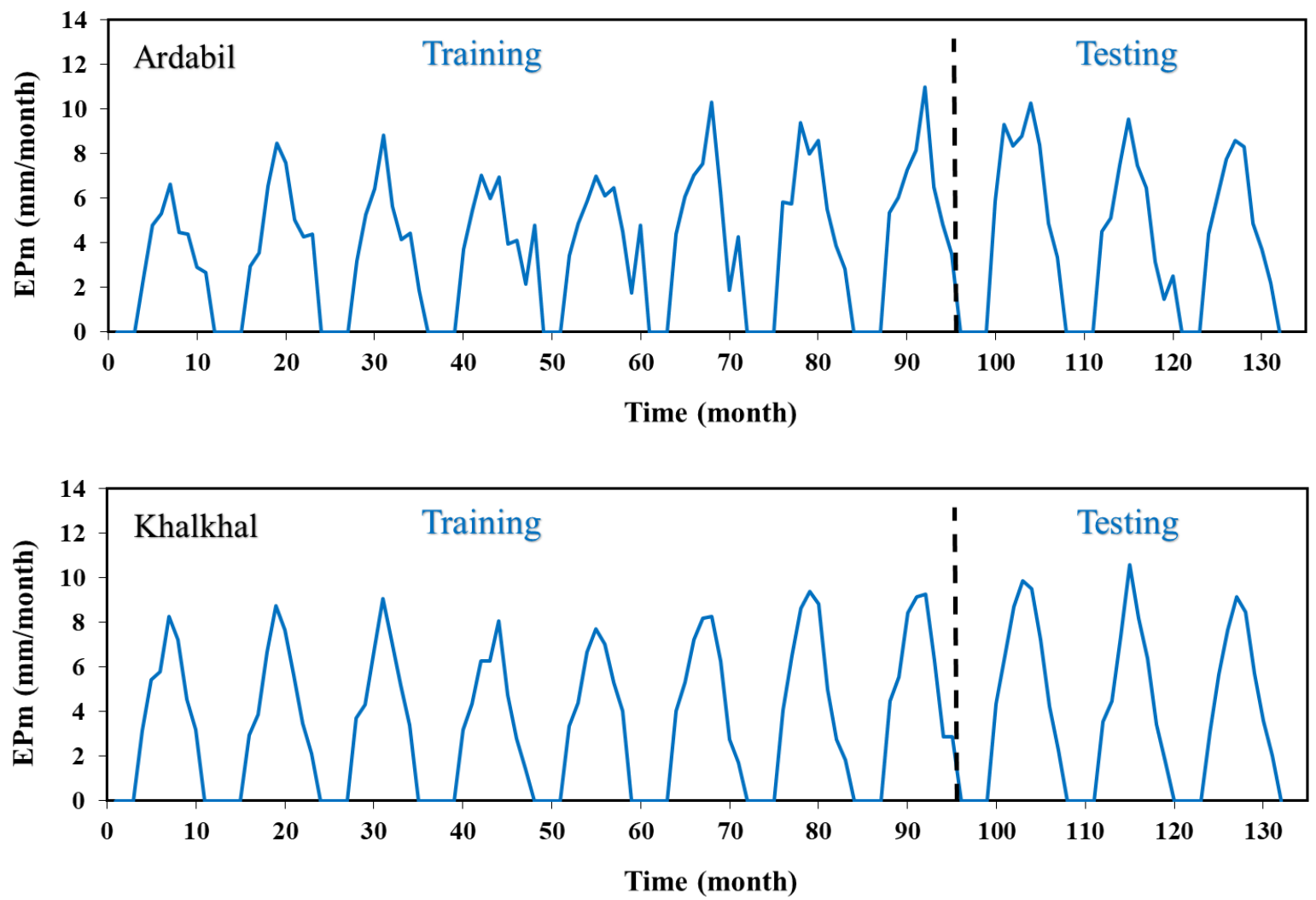

Fig. 2. Variation of the $E P_{m}$ time-series for the period 2009-2019 depicting the training and testing datasets in Ardabil and Khalkhal meteorological stations. 
Table 1. Summary statistics of the used data at Ardabil and Khalkhal observation stations.

\begin{tabular}{|c|c|c|c|c|c|c|c|}
\hline \multirow[b]{2}{*}{ Station } & \multirow[b]{2}{*}{$\begin{array}{l}\text { Data } \\
\text { Partition }\end{array}$} & \multirow[b]{2}{*}{ *Statistics } & \multicolumn{4}{|c|}{ Predictor Variables } & \multirow{2}{*}{$\begin{array}{l}\text { Objective Variable } \\
E P_{m}\left(\mathrm{~mm} . \text { month }^{-1}\right)\end{array}$} \\
\hline & & & $T\left({ }^{\circ} \mathrm{C}\right)$ & $S$ (hours) & $W(\mathrm{~m} / \mathrm{s})$ & $R H(\%)$ & \\
\hline \multirow{18}{*}{ Ardabil } & \multirow{6}{*}{ All data } & Min & -4.2 & 3.2 & 1.9 & 49 & 0 \\
\hline & & Max & 22.3 & 11.9 & 7.4 & 87.4 & 11 \\
\hline & & Ave & 10.2 & 7.1 & 3.7 & 70.8 & 3.8 \\
\hline & & SD & 7.1 & 2.11 & 0.93 & 7.33 & 3.17 \\
\hline & & Sk & -0.13 & 0.38 & 1 & -0.43 & 0.16 \\
\hline & & $\mathrm{CC}$ with $\mathrm{EP}_{\mathrm{m}}$ & 0.893 & 0.844 & -0.435 & -0.39 & 1 \\
\hline & \multirow[t]{6}{*}{ Training } & Min & -4.2 & 3.8 & 2.0 & 49 & 0 \\
\hline & & Max & 21.0 & 11.9 & 7.4 & 84.4 & 11.0 \\
\hline & & Ave & 10.1 & 7.1 & 3.8 & 71.0 & 3.7 \\
\hline & & SD & 7.1 & 2.03 & 0.93 & 7.38 & 3.02 \\
\hline & & Sk & -0.14 & 0.37 & 1.15 & -0.59 & 0.15 \\
\hline & & $\mathrm{CC}$ with $\mathrm{EP}_{\mathrm{m}}$ & 0.882 & 0.831 & -0.465 & -0.317 & 1 \\
\hline & \multirow[t]{6}{*}{ Testing } & Min & -3.66 & 3.19 & 1.91 & 57.10 & 0 \\
\hline & & Max & 22.3 & 11.4 & 6.4 & 87.4 & 10.3 \\
\hline & & Ave & 10.5 & 7.2 & 3.7 & 70.5 & 4.2 \\
\hline & & SD & 7.2 & 2.33 & 0.93 & 7.28 & 3.55 \\
\hline & & Sk & -0.1 & 0.38 & 0.64 & 0.02 & 0.09 \\
\hline & & $\mathrm{CC}$ with $\mathrm{EP}_{\mathrm{m}}$ & 0.927 & 0.869 & -0.362 & -0.562 & 1 \\
\hline \multirow{18}{*}{ Khalkhal } & \multirow{6}{*}{ All data } & Min & -6 & 3.3 & 0.8 & 35.4 & 0 \\
\hline & & Max & 24.4 & 12.6 & 5.0 & 80.2 & 10.6 \\
\hline & & Ave & 9.3 & 7.7 & 2.3 & 59.2 & 3.6 \\
\hline & & SD & 8.32 & 2.57 & 0.84 & 10.16 & 3.30 \\
\hline & & Sk & -0.04 & 0.19 & 0.66 & -0.17 & 0.31 \\
\hline & & $\mathrm{CC}$ with $\mathrm{EP}_{\mathrm{m}}$ & 0.955 & 0.931 & 0.546 & -0.868 & 1 \\
\hline & \multirow[t]{6}{*}{ Training } & Min & -4.5 & 3.8 & 0.9 & 37.5 & 0 \\
\hline & & Max & 21.7 & 12.6 & 5 & 80.2 & 9.4 \\
\hline & & Ave & 9.2 & 7.7 & 2.5 & 59.9 & 3.5 \\
\hline & & SD & 8.24 & 2.51 & 0.85 & 9.91 & 3.19 \\
\hline & & Sk & -0.05 & 0.19 & 0.55 & -0.10 & 0.29 \\
\hline & & $\mathrm{CC}$ with $\mathrm{EP}_{\mathrm{m}}$ & 0.955 & 0.928 & 0.609 & -0.852 & 1 \\
\hline & \multirow[t]{6}{*}{ Testing } & Min & -6 & 3.3 & 0.8 & 35.4 & 0 \\
\hline & & Max & 24.4 & 12.0 & 2.8 & 74.4 & 10.6 \\
\hline & & Ave & 9.6 & 7.7 & 1.8 & 57.2 & 4.0 \\
\hline & & SD & 8.65 & 2.76 & 0.55 & 10.7 & 3.60 \\
\hline & & Sk & -0.01 & 0.18 & -0.06 & -0.28 & 0.28 \\
\hline & & $\mathrm{CC}$ with $\mathrm{EP}_{\mathrm{m}}$ & 0.961 & 0.942 & 0.726 & -0.905 & 1 \\
\hline
\end{tabular}

*Min, Minimum; Max, Maximum; Ave, Average; SD, Standard deviation; Sk, skewness; CC, Correlation Coefficient. 

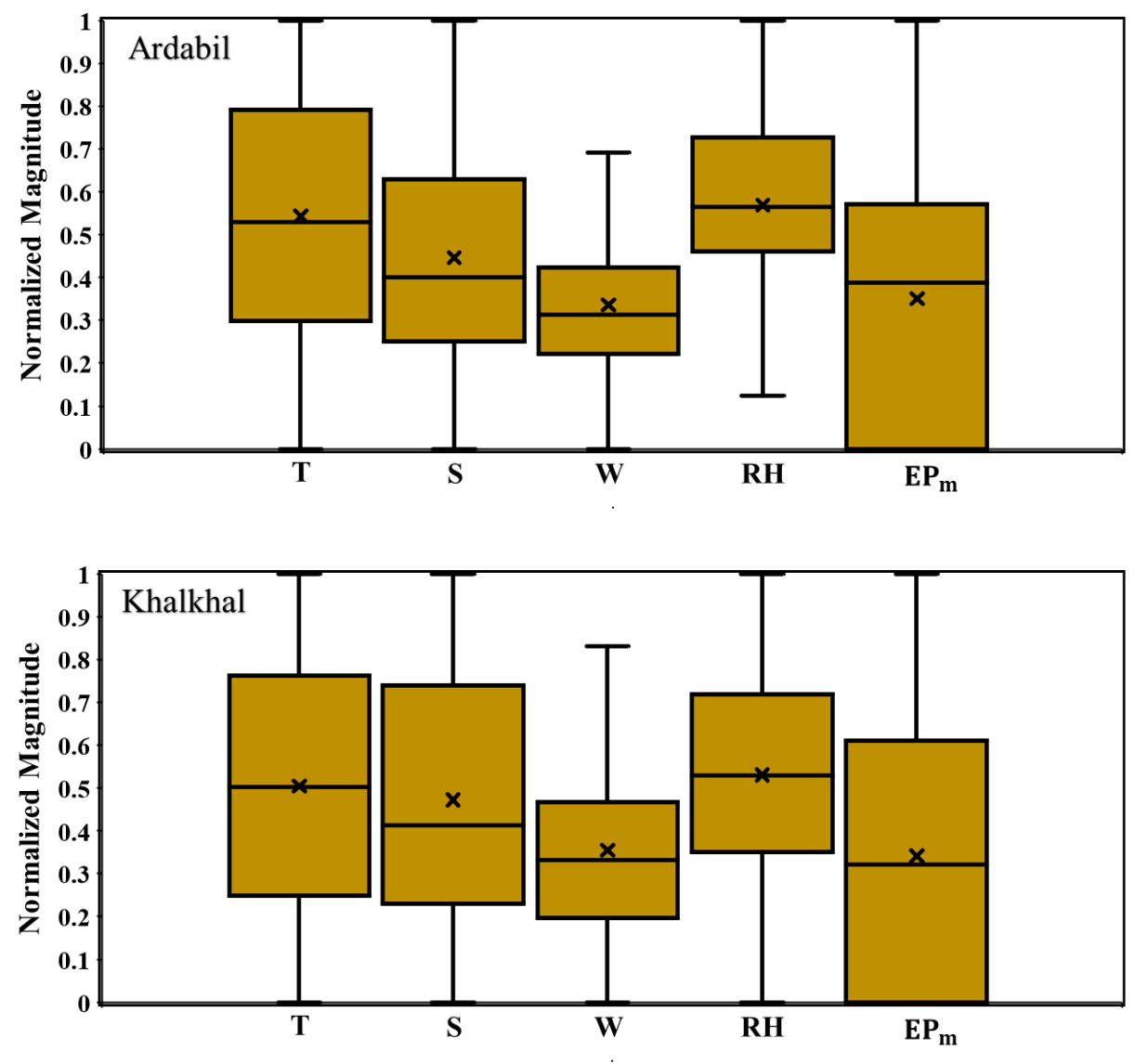

Fig. 3. Boxplot of Normalized Predictor and Objective variables.

Three methods of artificial neural network (ANN), support vector machine (SVM) and integration strategy of multiple models based on support vector machine (MM-SVM) have been used in the present study.

\subsection{Artificial neural network (ANN)}

For years, the ANN method has been recognized as a reliable tool with a mathematical structure for data processing and mimics the biological processes and neural power of the human brain (Bhagat et al. 2020). Artificial neural networks were first introduced by (Rosenblatt 1958) as perceptron networks. This method is based on complex internal theory and parallel processes of biological nervous systems and its ability to communicate the inputs and outputs of a process without full knowledge of its physics. Artificial neural networks use real output data to target output, which is network training (Tao et al. 2019). In general, an ANN model consists of three layers including input, hidden and output layers, the input layers containing the studied variables and the output layer containing the expected results. The hidden layer, which the number of that 
determined using a trial-and-error process, includes transfer functions to train and process input variables in nodes (Aytek et al. 2008). Each layer also contains a number of nerve cells (neurons) that are introduced as the main building blocks of the network. Neural networks are divided into four categories according to the direction of information entry and processing: Feedforward networks, Feedback networks, networks of radial basis functions and time reversal propagation networks. The most common type of neural network that is used to approximate functions and has been used in the present study is the Feedforward neural network with backpropagation algorithm based on gradient reduction and more than $90 \%$ of existing research on The application of ANN in water resources management has been done using it (Maier and Dandy 2000). The general structure of an ANN model is shown in Fig. 4 (Qasem et al. 2019). In the present study, by considering a hidden layer as a constant, trial and error was performed to determine the number of nerve cells in the hidden layer to achieve the minimum error in the range between 1 and 10 nerve cells.

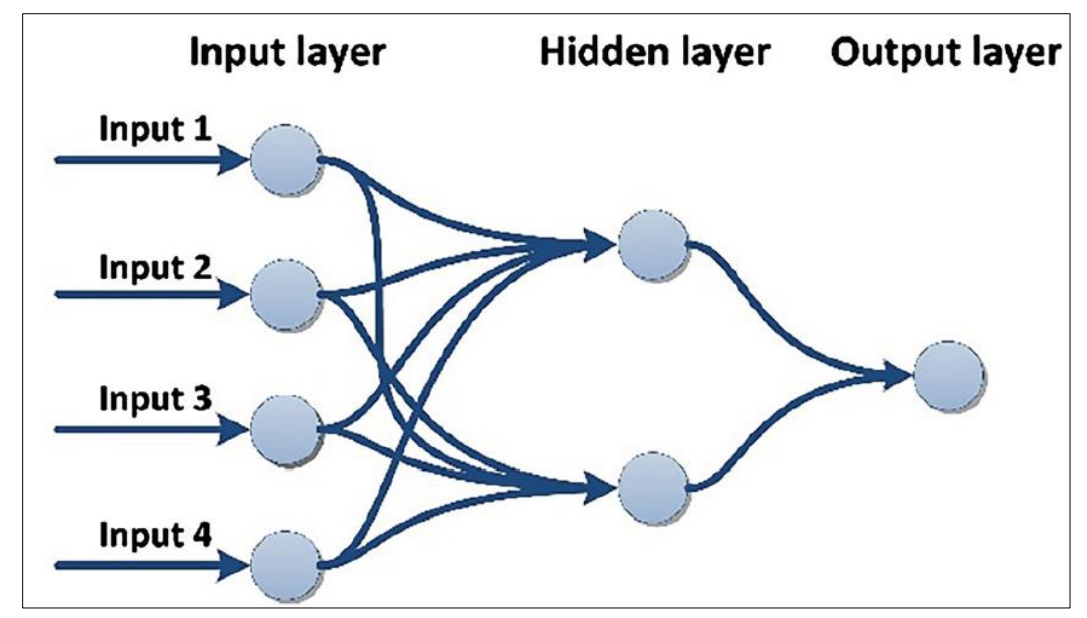

Fig. 4. General structure of an artificial neural network (ANN).

\subsection{Support vector machine (SVM)}

SVM is known as a non-statistical binary classifier that has attracted the attention of many researchers in recent years (Mantero et al. 2005; Naganna et al. 2019). SVM models are divided into two main groups: Support Vector Classification model and Support vector Regression model. SVC models are used to solve data classification problems that fall into different classes, and the SVR model is used to solve prediction problems (Vapnik 1995). Among the properties of SVM models, the following can be mentioned:

1) Applies maximum generalization in the design of classifiers. 
2) Ability to find the optimal answer of the function.

3) In solving classification problems, it automatically prepares the optimal structure and mechanism.

4) Using nonlinear kernels as well as internal multiplication capability in Hilbert spaces, it can model nonlinear functions.

SVM is known as an algorithm that searches for unique linear models and determines the maximum margin of the cloud using them. Maximizing the margin of the cloud page leads to maximizing the separation between classes and increasing the accuracy of the modeling process. Support vectors are the closest training points at the edge of the cloud and are used to define the boundary between classes (Shin et al. 2005). If the data is linear and separate, the SVM uses linear machines to separate and train an optimal level with the least error and the maximum distance between the page and the nearest training points (Support vectors) (Shin et al. 2005).

If the training points are in the form of $\left[x_{i}, y_{j}\right]$ and the input vector is in the form of $x_{i} \in R^{n}$, then the value of each class is defined as $y_{i} \in[-1,1] i=1, \ldots, i$. The decision rules that can then be expressed by an optimal page that separates binary decision classes can be expressed as Eqs. (1):

$Y=\operatorname{sgn}\left(\sum_{i=1}^{N} y_{i} a_{i}\left(X \times X_{i}\right)+b\right)$

In the above relation, $\mathrm{Y}$ as the output of the relation, $y_{\mathrm{i}}$ the value of the sample class, $\mathrm{X}_{\mathrm{i}}$, $\mathrm{a}_{\mathrm{i}}$ and $\mathrm{b}$ are the parameters that determine the hyperplane. If linear separation is not possible, then Eqs. (1) is changed as follows:

$Y=\operatorname{sgn}\left(\sum_{i=1}^{N} y_{i} a_{i} K\left(X \times X_{i}\right)+b\right)$

In Eqs. (2), $\mathrm{K}\left(\mathrm{X} \times \mathrm{X}_{\mathrm{i}}\right)$ is a kernel function that generates internal multiplications to create SVM models with different modes of nonlinear decision levels in the data space, and for this purpose it is necessary to define the line equation. The line equation in 2D space is calculated by Eqs. (3), the plane equation by Eqs. (4) and the screen equation by Eqs. (5) (Chen et al. 2002).

$$
\begin{aligned}
& \mathrm{w}_{1} \mathrm{x}_{1}+\mathrm{w}_{2} \mathrm{x}_{2}+\mathrm{b}=0 \\
& \mathrm{w}_{1} \mathrm{x}_{1}+\mathrm{w}_{2} \mathrm{x}_{2}+\mathrm{w}_{3} \mathrm{x}_{3}+\mathrm{b}=0 \\
& \sum_{i=1}^{n} w_{i} x_{i}+b=0 \rightarrow w^{T} x+b=0, w=\left[\begin{array}{c}
w_{1} \\
\mathrm{M} \\
w_{i}
\end{array}\right], x=\left[\begin{array}{c}
x_{1} \\
\mathrm{M} \\
x_{i}
\end{array}\right]
\end{aligned}
$$


According to Fig. 5, the continuous bold line with the equation $w^{T} x+b=0$ is known as the line separating the data on the plane and divides them into two categories A and $\mathrm{B}$. This line leads to the formation of a space in which the data belonging to category A take a positive number and the data belonging to category B take a negative number. But in SVM models, in addition to using the delimiter line, a confidence margin is also used for classification (Fig. 5). In this case, none of the data is allowed to be in the middle area. Assuming that the line with the equation $w^{T} x+b=0$ is a boundary zero point, so for the data, depending on the position in classes $\mathrm{A}$ and $\mathrm{B}$, respectively, the equations $\mathrm{w}^{\mathrm{T}} \mathrm{x}+\mathrm{b}>1$ and $\mathrm{w}^{\mathrm{T}} \mathrm{x}+\mathrm{b}<-1$ is established. The thickness of the separator in the SVM includes an area and makes the classification process more resistant to the risk of misalignment (Ehteram et al. 2020).

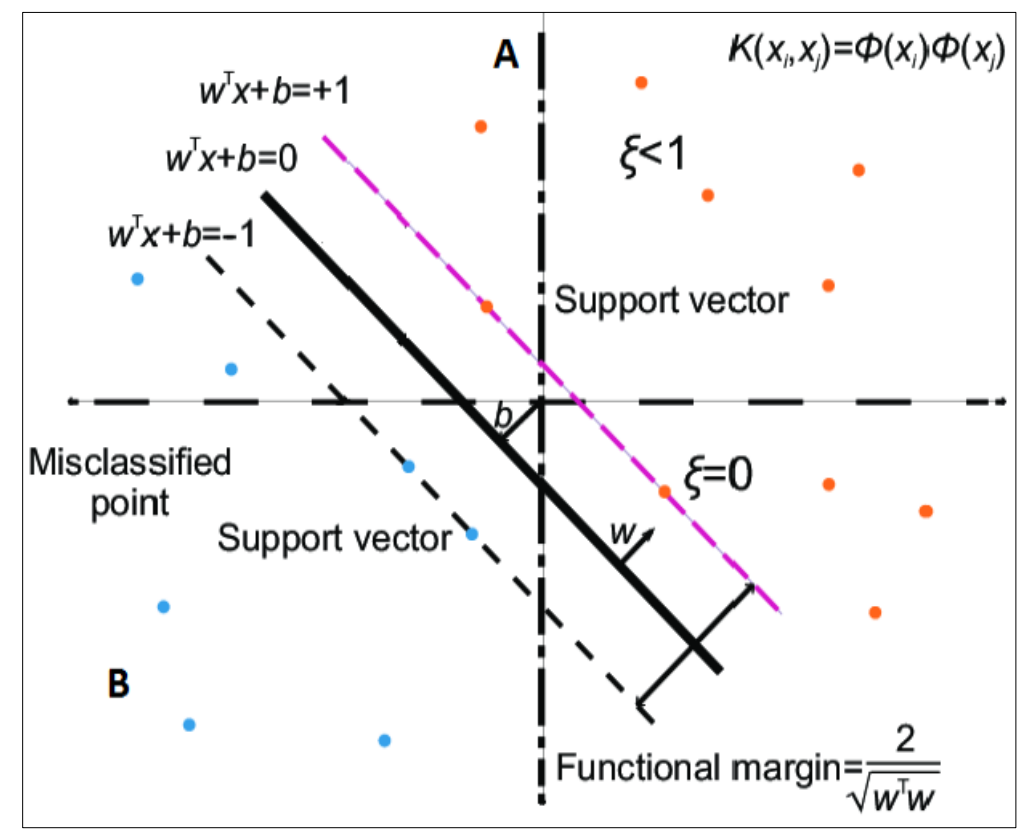

Fig. 5. Graphic display of Support vectors.

One of the common methods for solving nonlinear problems is to use kernel functions. In fact, with a nonlinear transformation of the input space into a larger space, usury issues can be separated linearly. The choice of kernel function is very important in SVM models and different issues can be considered depending on the nature of the problem. Therefore, a function cannot be definitively introduced as the most suitable function for SVM. The types of important kernel functions that are common in engineering applications and have been used in the present study are as shown in Table 2. 
Table 2. The kernel functions used in the present study.

\begin{tabular}{ll}
\hline Function type & Kernel function \\
Polynomial kernel function & $k\left(x_{i}, x_{j}\right)=\left(x_{i}^{T} x_{j}+1\right)^{p}$ \\
Radial based kernel function (RBF) & $k\left(x_{i}, x_{j}\right)=e^{-y\left|x_{i}-x_{j}\right|^{2}}$ \\
Pearson kernel function (PUK) & $k\left(x_{i}, x_{j}\right)=\frac{1}{\left[1+\left(2 \sqrt{\left|x_{i}-x_{j}\right|^{2}} \times \sqrt{2^{\frac{1}{\omega}}}\right)^{2}\right]^{\omega}}$
\end{tabular}

\subsection{Multiple model-support vector machine (MM-SVM)}

The use of multiple models based on support vector machine (MM-SVM) with the aim of increasing the accuracy in estimating $E P_{m}$ and comparison with other models in the present study was on the agenda, which is a new hybrid model. This hybrid model is achieved in two stages: In the first stage, the learning process of artificial intelligence models (i.e., ANN and SVM) was performed by considering meteorological data as input and $E P_{m}$ data as output. Then the prediction process in the second stage began with the help of the results obtained from the first stage. In other words, a kind of binary learning process begins under the machine learning modeling strategy. The only common denominator in both stages is the use of data (i.e., $E P_{m}$ ) as the output of the models. According to Fig. 6, the input data to the SVM model in the second stage is the same as the output data in the model learning process in the first stage (i.e., the outputs of the two models ANN and SVM).

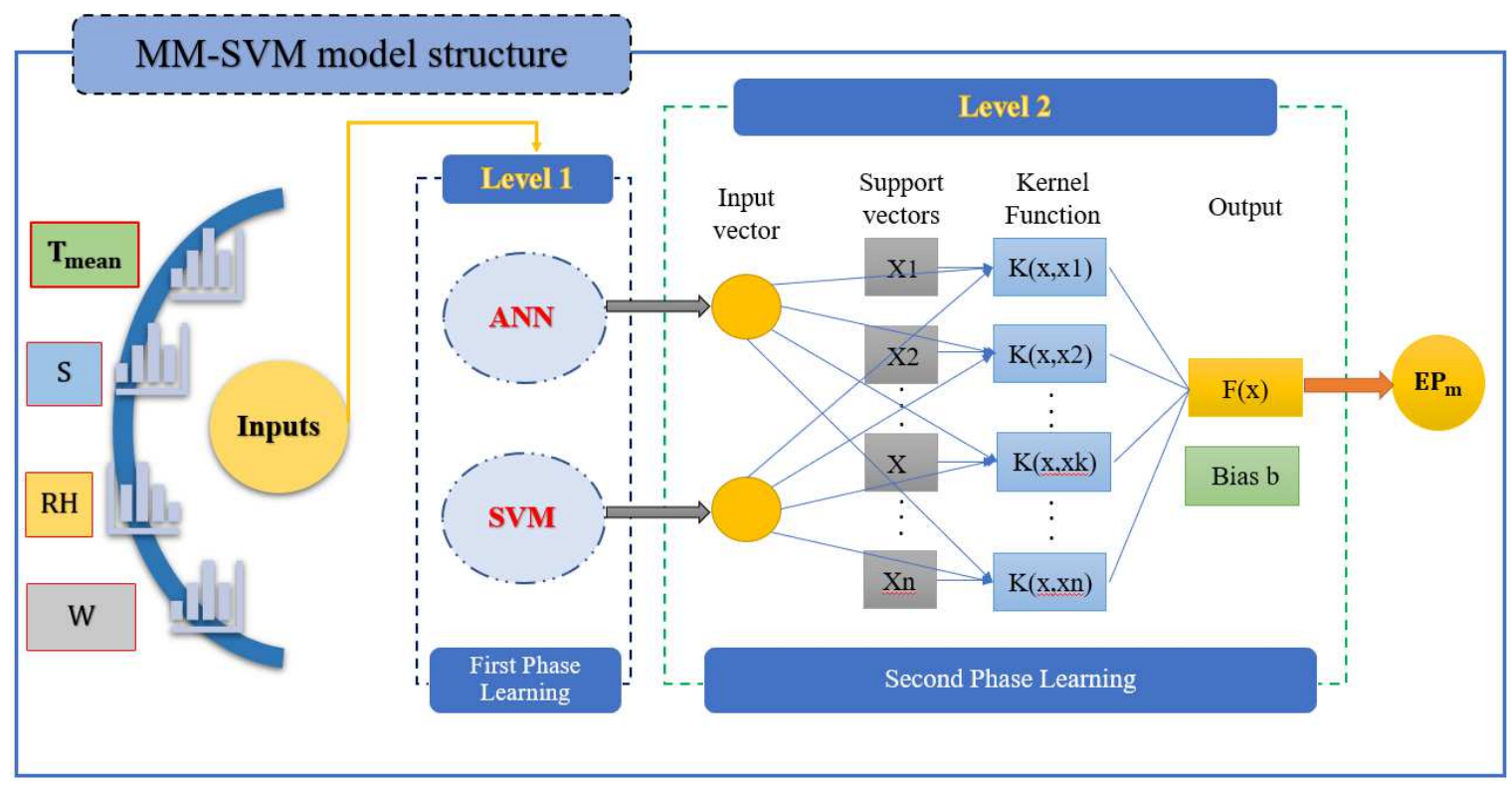

Fig. 6. Overall structure of the MM-SVM model. 


\subsection{Model performance evaluation indicators}

To evaluate the accuracy of ANN, SVM and MM-SVM models according to the equations 6 to 9, the performance evaluation criteria of mean square root error (RMSE), mean absolute error (MAE), Kling-Gupta (KGE) and coefficient of determination $\left(\mathrm{R}^{2}\right)$ were used. The RMSE measures the best fit with the priority of high values of $E P_{m}$, while the MAE applies a more balanced view of the fit to the average values of $E P_{m}$ (Tung and Yaseen 2020; Yaseen et al. 2019). The KGE criterion in equation 8 is one of the new criteria in the evaluation of hydrological models proposed by (Gupta et al. 2009) and is in fact a modified version of the Nash-Sutcliffe efficiency (NSE) index.

$$
\begin{aligned}
& R M S E=\sqrt{\frac{1}{n} \sum_{i=1}^{n}\left(x_{i}-y_{i}\right)^{2}} \\
& M A E=\frac{1}{n} \sum_{i=1}^{n}\left|x_{i}-y_{i}\right| \\
& K G E=1-\sqrt{(c c-1)^{2}+(\alpha-1)^{2}+(\beta-1)^{2}} \\
& R^{2}=\left(\frac{\left(\sum_{i=1}^{n} x_{i} y_{i}-\frac{1}{n} \sum_{i=1}^{n} x_{i} \sum_{i=1}^{n} y_{i}\right)}{\left(\sum_{i=1}^{n} x_{i}^{2}-\frac{1}{n}\left(\sum_{i=1}^{n} x_{i}\right)^{2}\right)\left(\sum_{i=1}^{n} y_{i}^{2}-\frac{1}{n}\left(\sum_{i=1}^{n} y_{i}\right)^{2}\right.}\right)^{2}
\end{aligned}
$$

In equations 6 to 9, $\mathrm{x}_{\mathrm{i}}$ and $\mathrm{y}_{\mathrm{i}}$ are real and estimated values, $\mathrm{n}$ is the number of data evaluated, $\mathrm{cc}$ is the linear correlation coefficient between $\mathrm{x}_{\mathrm{i}}$ and $\mathrm{y}_{\mathrm{i}}, \alpha$ is equal to the ratio of standard deviation $\mathrm{y}_{\mathrm{i}}$ to standard deviation $\mathrm{x}_{\mathrm{i}}$ and $\beta$ is equal to the ratio of average $\mathrm{y}_{\mathrm{i}}$ to the average is $\mathrm{x}_{\mathrm{i}}$.

\section{Results and discussion}

\subsection{Determining the most effective input compounds to models.}

Based on the statistical characteristics of meteorological variables in Table 1, in the present study, seven different input scenarios were considered to the models (Table 3). Because $T$ variable had the highest correlation with the $E P_{m}$ variable, it was used in all input compounds with the aim of increasing the $E P_{m}$ prediction accuracy. 
Table 3. The different input combinations and model designations used in this study.

\begin{tabular}{llcccc}
\hline & & & \multicolumn{3}{c}{ Models } \\
\cline { 5 - 6 } Scenario No. & $\begin{array}{l}\text { Predictor Variables } \\
\text { (Input) }\end{array}$ & $\begin{array}{c}\text { Objective Variable } \\
\text { (Output) }\end{array}$ & ANN & SVM & MM-SVM \\
\hline 1 & $T, R H$ & $E P_{m}$ & ANN-1 & SVM-1 & MM-SVM-1 \\
2 & $T, W$ & $E P_{m}$ & ANN-2 & SVM-2 & MM-SVM-2 \\
3 & $T, S H$ & $E P_{m}$ & ANN-3 & SVM-3 & MM-SVM-3 \\
4 & $T, R H, W$ & $E P_{m}$ & ANN-4 & SVM-4 & MM-SVM-4 \\
5 & $T, R H, S H$ & $E P_{m}$ & ANN-5 & SVM-5 & MM-SVM-5 \\
6 & $T, W, S H$ & $E P_{m}$ & ANN-6 & SVM-6 & MM-SVM-6 \\
7 & $T, R H, W, S H$ & $E P_{m}$ & ANN-7 & SVM-7 & MM-SVM-7 \\
\hline
\end{tabular}

\subsection{Simulation of $E P_{m}$ at Ardabil station}

$E P_{m}$ values at Ardabil station were predicted or simulated during 7 scenarios in two stages of training and testing using ANN, SVM and MM-SVM methods based on evaluation with RMSE, $\mathrm{MAE}, \mathrm{KGE}$ and $\mathrm{R}^{2}$ criteria. The values of the evaluation criteria for all scenarios and models are shown in Table 4. 
Table 4. Values of the RMSE (mm. month ${ }^{-1}$ ), MAE (mm. month ${ }^{-1}$ ), KGE and $\mathrm{R}^{2}$ criteria for the developed models during training and testing periods at Ardabil station.

\begin{tabular}{|c|c|c|c|c|c|c|c|c|c|}
\hline \multirow{3}{*}{ Scenario No. } & \multirow{3}{*}{$\begin{array}{l}\text { Station } \\
\text { Model }\end{array}$} & \multicolumn{8}{|c|}{ Ardabil } \\
\hline & & \multicolumn{4}{|l|}{ Training } & \multicolumn{4}{|l|}{ Testing } \\
\hline & & $\begin{array}{c}\text { RMSE } \\
\left(\mathrm{mm} . \text { month }^{-1}\right)\end{array}$ & $\begin{array}{c}\text { MAE } \\
\left(\mathrm{mm} \cdot \text { month }^{-1}\right)\end{array}$ & KGE & $\mathrm{R}^{2}$ & $\begin{array}{c}\text { RMSE } \\
\left(\mathrm{mm} \cdot \text { month }^{-1}\right)\end{array}$ & $\begin{array}{c}\text { MAE } \\
\left(\mathrm{mm} \cdot \text { month }^{-1}\right)\end{array}$ & KGE & $\mathrm{R}^{2}$ \\
\hline \multirow{3}{*}{1} & ANN & 1.187 & 0.867 & 0.880 & 0.844 & 1.429 & 1.112 & 0.796 & 0.851 \\
\hline & SVM & 1.126 & 0.645 & 0.905 & 0.868 & 1.355 & 1.031 & 0.814 & 0.872 \\
\hline & MM-SVM & 1.146 & 0.612 & 0.904 & 0.867 & 1.389 & 1.003 & 0.829 & 0.865 \\
\hline \multirow{3}{*}{2} & ANN & 1.145 & 0.848 & 0.892 & 0.855 & 1.330 & 1.038 & 0.790 & 0.881 \\
\hline & SVM & 1.164 & 0.739 & 0.911 & 0.856 & 1.270 & 0.929 & 0.797 & 0.903 \\
\hline & MM-SVM & 1.168 & 0.719 & 0.921 & 0.853 & 1.154 & 0.817 & 0.806 & 0.922 \\
\hline \multirow{3}{*}{3} & ANN & 1.182 & 0.892 & 0.885 & 0.845 & 1.370 & 1.046 & 0.816 & 0.863 \\
\hline & SVM & 1.200 & 0.753 & 0.899 & 0.846 & 1.357 & 0.976 & 0.804 & 0.882 \\
\hline & MM-SVM & 1.232 & 0.726 & 0.890 & 0.846 & 1.417 & 0.986 & 0.800 & 0.875 \\
\hline \multirow{3}{*}{4} & ANN & 1.062 & 0.719 & 0.908 & 0.875 & 1.246 & 0.987 & 0.820 & 0.887 \\
\hline & SVM & 0.948 & 0.494 & 0.927 & 0.903 & 1.213 & 0.945 & 0.805 & 0.905 \\
\hline & MM-SVM & 0.960 & 0.472 & 0.929 & 0.902 & 1.177 & 0.878 & 0.825 & 0.909 \\
\hline \multirow{3}{*}{5} & ANN & 1.064 & 0.748 & 0.907 & 0.875 & 1.202 & 0.967 & 0.841 & 0.894 \\
\hline & SVM & 1.027 & 0.551 & 0.912 & 0.891 & 1.249 & 0.931 & 0.849 & 0.888 \\
\hline & MM-SVM & 1.057 & 0.542 & 0.907 & 0.887 & 1.251 & 0.897 & 0.855 & 0.891 \\
\hline \multirow{3}{*}{6} & ANN & 1.129 & 0.840 & 0.895 & 0.859 & 1.228 & 0.932 & 0.819 & 0.896 \\
\hline & SVM & 1.091 & 0.643 & 0.909 & 0.872 & 1.179 & 0.885 & 0.795 & 0.926 \\
\hline & MM-SVM & 1.088 & 0.624 & 0.922 & 0.872 & 1.088 & 0.790 & 0.810 & 0.939 \\
\hline \multirow{3}{*}{7} & ANN & 1.041 & 0.709 & 0.911 & 0.880 & 1.168 & 0.930 & 0.837 & 0.902 \\
\hline & SVM & 0.907 & 0.438 & 0.939 & 0.912 & 1.136 & 0.872 & 0.853 & 0.907 \\
\hline & MM-SVM & 0.916 & 0.426 & 0.936 & 0.911 & 1.109 & 0.813 & 0.862 & 0.912 \\
\hline
\end{tabular}

According to the results of evaluation criteria in the test phase (Table 4), the best result of the ANN model in scenario 7 (ANN-7) with RMSE $=1.168 \mathrm{~mm} . \mathrm{month}^{-1}, \mathrm{MAE}=0.930 \mathrm{~mm} . \mathrm{month}^{-1}, \mathrm{KGE}$ $=0.862$ and $\mathrm{R}^{2}=0.902$. It is observed that the value of KGE statistic is more than 0.7 , which is a relatively good result. The best result of SVM model as ANN-7 model in scenario 7 (SVM-7) with $\mathrm{RMSE}=1.136 \mathrm{~mm}$. month $^{-1}, \mathrm{MAE}=0.872 \mathrm{~mm}$. month $^{-1}, \mathrm{KGE}=0.853$ and $\mathrm{R}^{2}=0.907$ has been recorded. While the new hybrid model MM-SVM was able to have the best result among the ANN and SVM models with the first rank. This is observed in Scenario 6 (MM-SVM-6) with RMSE = $1.088 \mathrm{~mm}$. month $^{-1}$, MAE $=0.790 \mathrm{~mm}$. month $^{-1}, \mathrm{KGE}=0.819$ and $\mathrm{R}^{2}=0.939$. Therefore, MMSVM-6, SVM-7 and ANN-7 models were determined as the best models in predicting $E P_{m}$ at Ardabil station, respectively. It is clear from Table 4 that ANN, SVM, and MM-SVM models are 
sensitive to the correlation between input and output $\left(E P_{m}\right)$ variables, and the best results occur when the variables with the highest correlation with $E P_{m}$ as input Models are considered (i.e., Scenario 6 (Including $T, W$ and $S$ ) and Scenario 7 (Including $T, R H, W$ and $S$ )). On the other hand, considering that the number of input variables in Scenario 6 is less than Scenario 7, so the MMSVM-6 model can be introduced as an optimal model with high accuracy in estimating $E P_{m}$ at Ardabil station. The core of the present study is to observe the behavioral pattern of the new MMSVM hybrid model in $E P_{m}$ prediction based on the results of evaluation criteria of different scenarios. Accordingly, with accuracy in Table 4 can be observed incremental, constant and decreasing accuracy behavior in the RMSE and $\mathrm{R}^{2}$ criteria related to the scenarios compared to the criteria of ANN and SVM models in the test phase. The largest incremental change in prediction accuracy occurred in scenarios 2, 6, 4 and 7, respectively. Also, almost constant changes in the accuracy of the MM-SVM model compared to the two ANN and SVM models are shown in Scenario 5. The largest decrease in the prediction accuracy of the new model is also seen in scenarios 3 and 1 , respectively.

As shown in Fig. 7 (left side), $E P_{m}$ time series changes predicted for the superior models (ANN7, SVM-7 and MM-SVM-6) are compared with the observed $E P_{m}$ in the test phase (2017-2019). The observational and predicted scattering plots of the best ANN, SVM and MM-SVM models for the test phase are also shown in Fig. 7 (right side). From scatter plots in Fig. 7, it can be inferred that the estimates made by the MM-SVM-6 model at Ardabil station are relatively more consistent with the observed $E P_{m}$ values than other models. In other words, $E P_{m}$ values at Ardabil station can be estimated with acceptable accuracy with meteorological data on $T, W$ and $S$. It is also observed that the distribution of points drawn around the bisector axis in Fig. 7 is lower for the MM-SVM6 model and the model has shown a relatively higher accuracy. The important point of scatter plots is the low estimation of all three models in predicting $E P_{m}$, especially in high evaporation values, which is more evident in the MM-SVM-6 model. It can be said that unlike the ANN-7 and SVM7 models, the MM-SVM-6 model has a much lower estimate in $E P_{m}$ estimates. The prediction error of the superior models is also shown in Fig. 8. According to this figure, the MM-SVM-6 model was able to show better performance in predicting $E P_{m}$ in some months than the two models ANN-7 and SVM-7 and reported values close to reality. 


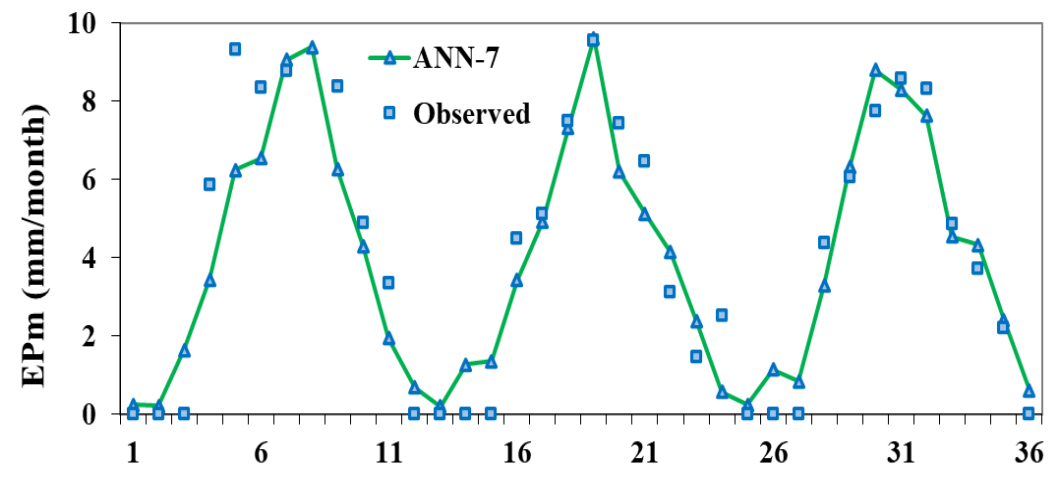

Time (month)

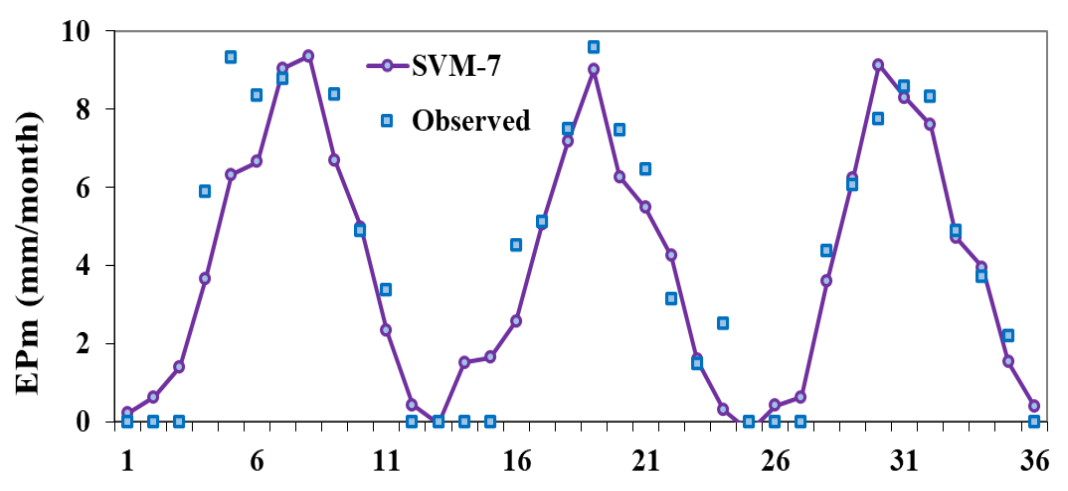

Time (month)

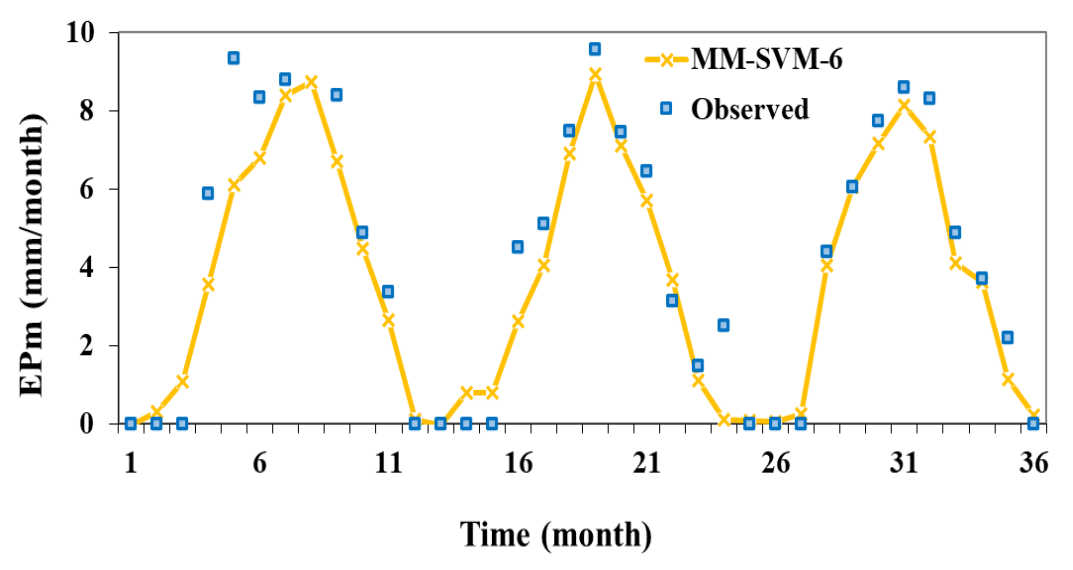

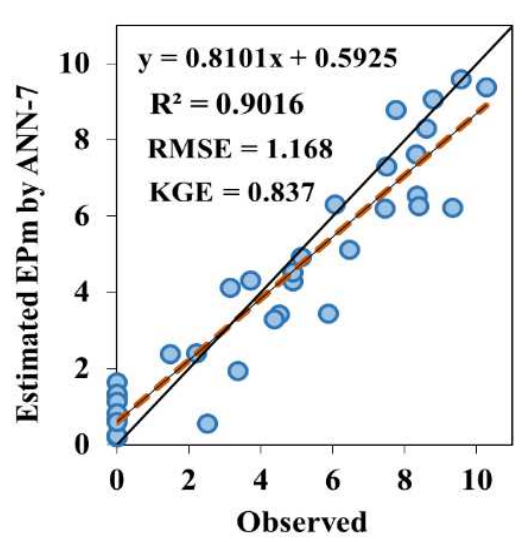
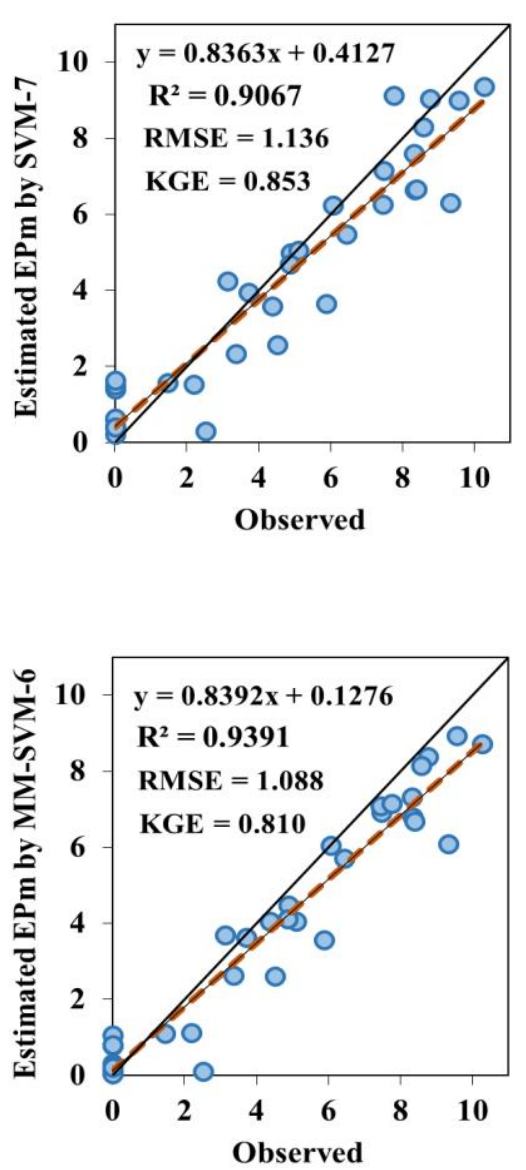

Fig. 7. Time series (left) and scatter (right) plots between observed and simulated $E P_{m}$ values by ANN-7, SVM-7 and MM-SVM-6 models during testing period at Ardabil station. 


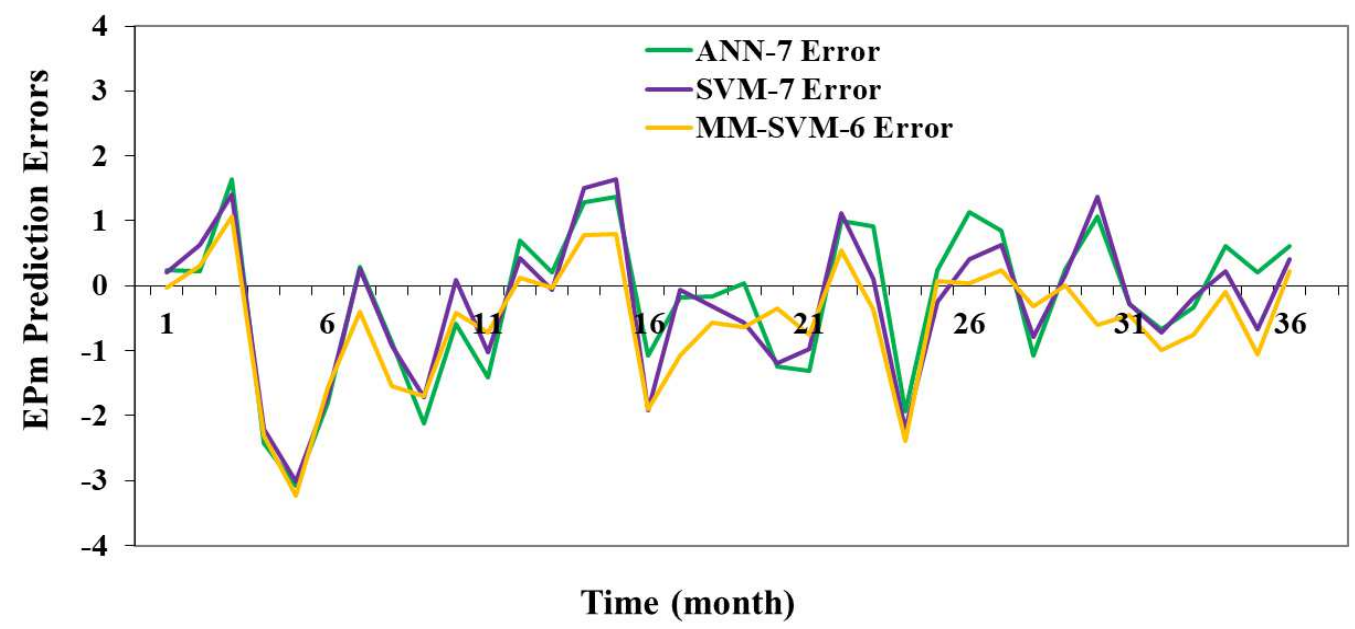

Fig. 8. $E P_{m}$ Prediction Errors plot by ANN-7, SVM-7 and MM-SVM-6 models during testing period at Ardabil station.

\subsection{Simulation of $E P_{m}$ at Khalkhal station}

According to Table 5, ANN, SVM and MM-SVM models showed different results in Khalkhal station compared to Ardabil station. So that the best result in the test phase with RMSE $=0.761$ $\mathrm{mm}$. month ${ }^{-1}, \mathrm{MAE}=0.54 \mathrm{~mm}$. month $^{-1}, \mathrm{KGE}=0.903$ and $\mathrm{R}^{2}=0.962$, in scenario 5 and Obtained by ANN model (ANN-5). MM-SVM model as the second top model with RMSE $=0.833 \mathrm{~mm}$. month $^{-1}, \mathrm{MAE}=0.568 \mathrm{~mm}$. month $^{-1}, \mathrm{KGE}=0.908$ and $\mathrm{R}^{2}=0.953$ in scenario $5(\mathrm{MM}-\mathrm{SVM}-5)$ and is selected at Khalkhal station. It can be seen that there is very little difference in terms of accuracy between the ANN-5 and MM-SVM-5 models, and even the KGE statistic in the MMSVM-5 model is slightly higher than the ANN-5. Unlike Ardabil station, which in connection with the combined model MM-SVM, we saw more incremental behavior in the accuracy of evaluation, in Khalkhal station, this case was observed in only one scenario. In other words, an increasing trend in the accuracy of the MM-SVM model was observed only in the fifth scenario and the other scenarios showed a decreasing trend in the evaluation accuracy compared to the two models ANN and SVM. The best result for SVM model is also in scenario 5 (SVM-5) with RMSE $=0.859 \mathrm{~mm}$. month $^{-1}, \mathrm{MAE}=0.57 \mathrm{~mm}$. month $^{-1}, \mathrm{KGE}=0.9$ and $\mathrm{R}^{2}=0.952$ Happened. According to Table (1), the variables of $T, R H$ and $S$ showed the highest correlation with $E P_{m}$ with CC values of 0.955, 0.868 and 0.931 , respectively, compared to the other input variables. Therefore, the reason for the absolute superiority of Scenario 5 over the other scenarios of Khalkhal station is the presence of $T, R H$ and $S$ variables within this scenario. 
Table 5. Values of the RMSE (mm. month ${ }^{-1}$ ), MAE (mm. month $\left.{ }^{-1}\right), \mathrm{KGE}$ and $\mathrm{R}^{2}$ criteria for the developed models during training and testing periods at Khalkhal station.

\begin{tabular}{|c|c|c|c|c|c|c|c|c|c|}
\hline \multirow{3}{*}{$\begin{array}{c}\text { Scenario } \\
\text { No. }\end{array}$} & \multirow{3}{*}{$\begin{array}{l}\text { Station } \\
\text { Model }\end{array}$} & \multicolumn{8}{|c|}{ Khalkhal } \\
\hline & & \multicolumn{4}{|l|}{ Training } & \multicolumn{4}{|l|}{ Testing } \\
\hline & & $\begin{array}{c}\text { RMSE } \\
\left(\mathrm{mm} . \text { month }^{-1}\right)\end{array}$ & $\begin{array}{c}\text { MAE } \\
\left(\mathrm{mm} \cdot \mathrm{month}^{-1}\right)\end{array}$ & KGE & $\mathrm{R}^{2}$ & $\begin{array}{c}\text { RMSE } \\
\left(\mathrm{mm} . \text { month }^{-1}\right)\end{array}$ & $\begin{array}{c}\text { MAE } \\
\left(\mathrm{mm} \cdot \text { month }^{-1}\right)\end{array}$ & KGE & $R^{2}$ \\
\hline \multirow{4}{*}{1} & ANN & 0.721 & 0.545 & 0.962 & 0.948 & 0.846 & 0.620 & 0.907 & 0.950 \\
\hline & SVM & 0.653 & 0.958 & 0.975 & 0.406 & 0.880 & 0.547 & 0.910 & 0.946 \\
\hline & MM-SVM & 0.660 & 0.382 & 0.974 & 0.957 & 0.963 & 0.585 & 0.895 & 0.936 \\
\hline & ANN & 0.686 & 0.517 & 0.966 & 0.953 & 0.878 & 0.697 & 0.851 & 0.957 \\
\hline \multirow[t]{3}{*}{2} & SVM & 0.641 & 0.417 & 0.971 & 0.959 & 0.999 & 0.775 & 0.834 & 0.946 \\
\hline & MM-SVM & 0.640 & 0.383 & 0.966 & 0.961 & 1.059 & 0.768 & 0.827 & 0.940 \\
\hline & ANN & 0.673 & 0.487 & 0.967 & 0.955 & 0.836 & 0.603 & 0.879 & 0.959 \\
\hline \multirow[t]{3}{*}{3} & SVM & 0.698 & 0.440 & 0.948 & 0.954 & 0.918 & 0.659 & 0.854 & 0.956 \\
\hline & MM-SVM & 0.693 & 0.693 & 0.953 & 0.955 & 0.991 & 0.675 & 0.850 & 0.945 \\
\hline & ANN & 0.680 & 0.515 & 0.964 & 0.954 & 0.868 & 0.652 & 0.868 & 0.955 \\
\hline \multirow[t]{3}{*}{4} & SVM & 0.580 & 0.323 & 0.961 & 0.967 & 0.972 & 0.694 & 0.855 & 0.945 \\
\hline & MM-SVM & 0.612 & 0.309 & 0.954 & 0.965 & 1.048 & 0.715 & 0.846 & 0.937 \\
\hline & ANN & 0.644 & 0.453 & 0.970 & 0.959 & 0.761 & 0.540 & 0.908 & 0.962 \\
\hline \multirow[t]{3}{*}{5} & SVM & 0.613 & 0.358 & 0.976 & 0.963 & 0.859 & 0.570 & 0.900 & 0.952 \\
\hline & MM-SVM & 0.591 & 0.388 & 0.974 & 0.965 & 0.833 & 0.568 & 0.903 & 0.953 \\
\hline & ANN & 0.656 & 0.490 & 0.968 & 0.957 & 0.874 & 0.679 & 0.850 & 0.960 \\
\hline \multirow[t]{3}{*}{6} & SVM & 0.628 & 0.361 & 0.974 & 0.961 & 0.925 & 0.682 & 0.866 & 0.951 \\
\hline & MM-SVM & 0.659 & 0.340 & 0.960 & 0.959 & 1.005 & 0.709 & 0.854 & 0.943 \\
\hline & ANN & 0.595 & 0.422 & 0.974 & 0.965 & 0.883 & 0.683 & 0.842 & 0.961 \\
\hline \multirow[t]{2}{*}{7} & SVM & 0.556 & 0.283 & 0.968 & 0.970 & 1.036 & 0.799 & 0.816 & 0.949 \\
\hline & MM-SVM & 0.595 & 0.275 & 0.959 & 0.967 & 1.068 & 0.794 & 0.809 & 0.947 \\
\hline
\end{tabular}

As shown in Fig. 9 (left side), $E P_{m}$ time series changes predicted for the superior models (ANN5, SVM-5 and MM-SVM-5) are compared with the observed $E P_{m}$ data in the test phase (20172019) at Khalkhal Station. The observational and predicted scattering plots of the best ANN, SVM and MM-SVM models for the test phase are also shown in Fig. 9 (right side). As shown in the time series plots, the ANN-5 and MM-SVM-5 models were able to provide more consistency with the observational data with relatively higher accuracy than the SVM-5 model. In other words, ANN5 and MM-SVM-5 models using temperature $(T)$, relative humidity $(R H)$ and sunshine hours $(S)$ variables can simulate $E P_{m}$ data with higher accuracy. Also, by carefully looking at the scatter plots of the top models, it can be seen that the distribution of points drawn around the bisector axis for ANN-5 and MM-SVM-5 models is less than the SVM-5 model, and these models They show higher accuracy. In addition, all three top models estimate the high $E P_{m}$ values with less accuracy, in other words, we saw a slightly lower estimate for the high $E P_{m}$ values in these models, and this 
point is slightly higher for the SVM-5 model. Fig. 10 shows that there is not much difference between the superior models in terms of errors in $E P_{m}$ prediction. However, it is clear that in most months the ANN-5 and MM-SVM-5 models were able to show less error than the SVM-5 model.
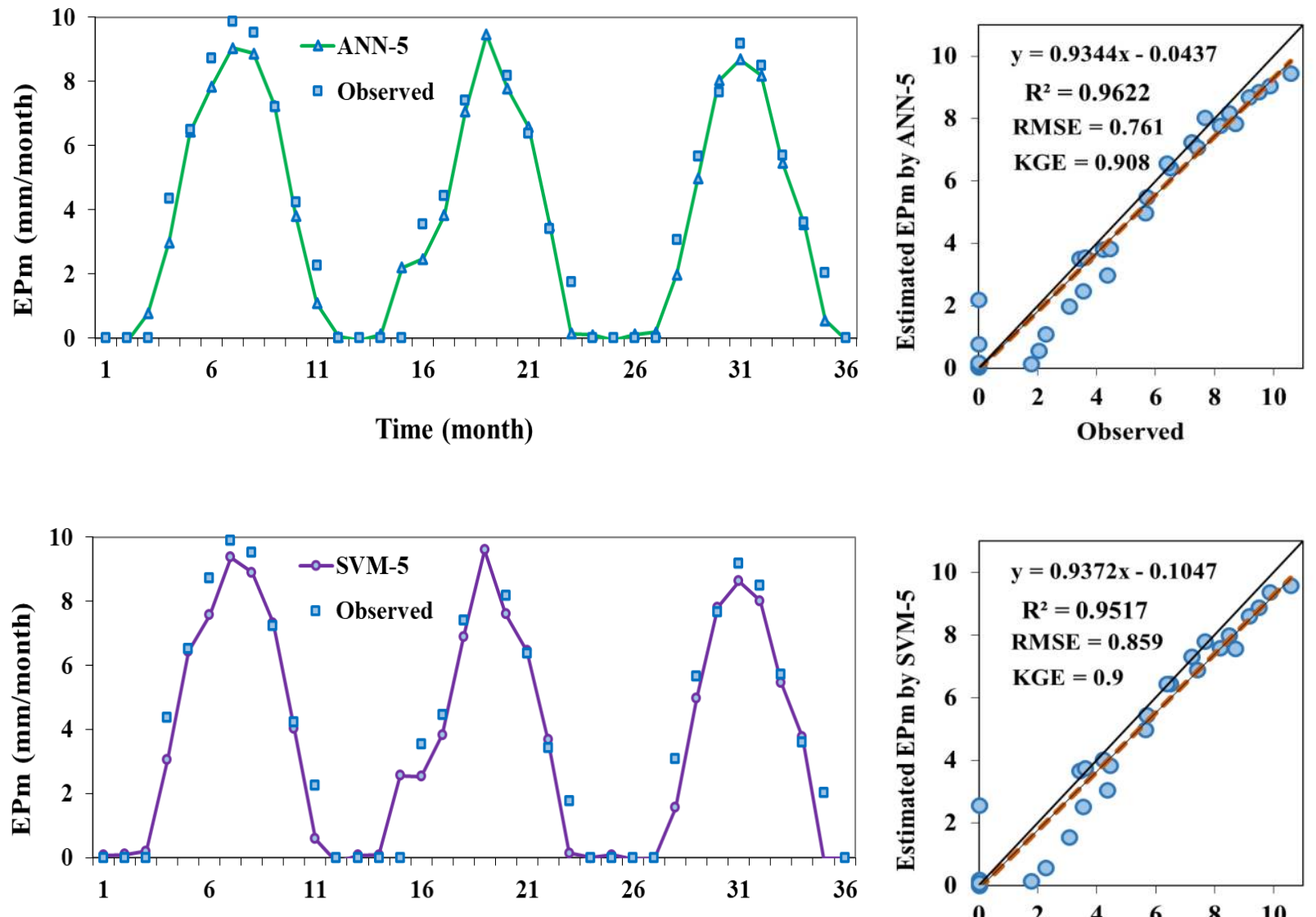

Time (month)
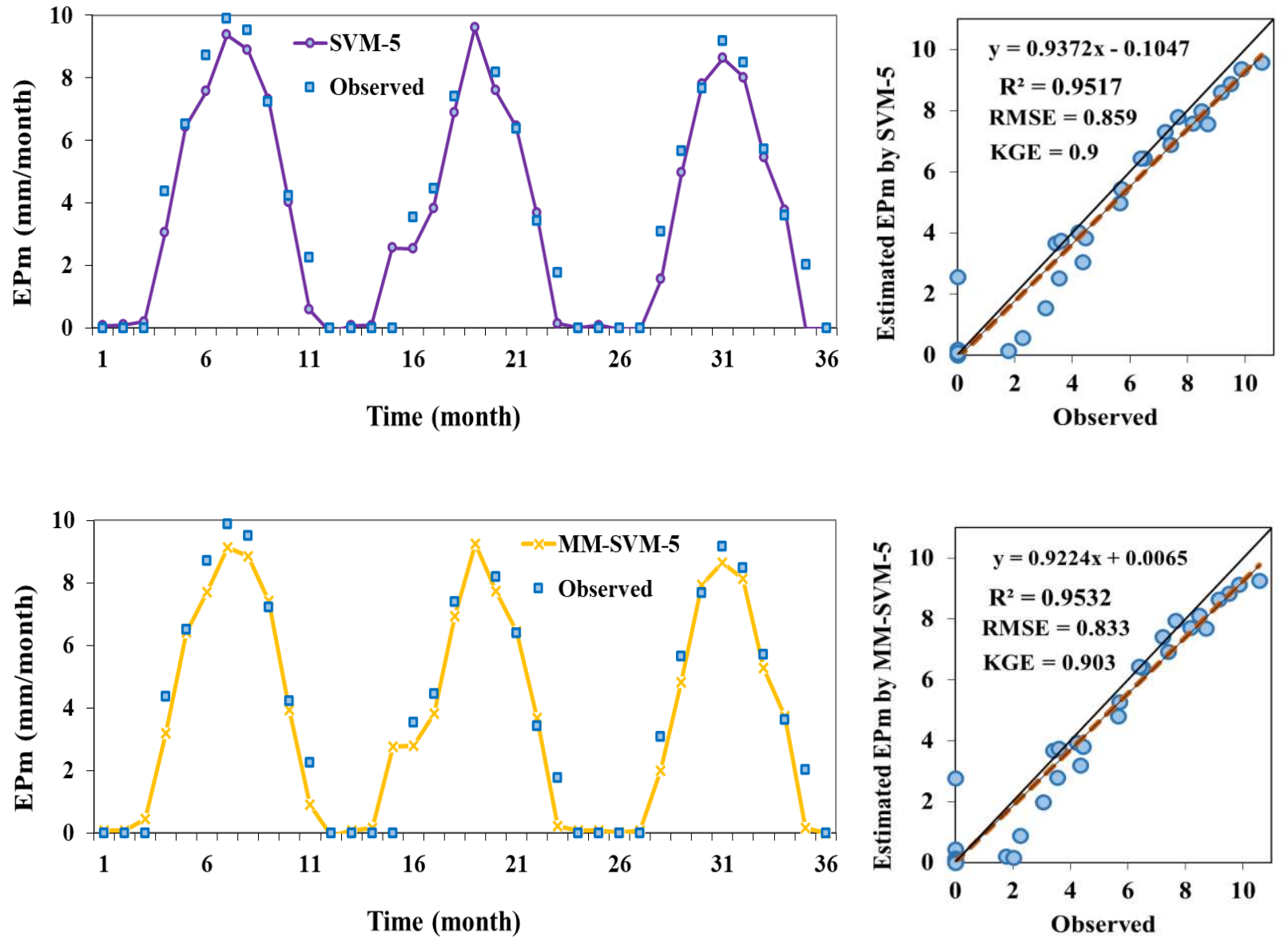
Fig. 9. Time series (left) and scatter (right) plots between observed and simulated $E P_{m}$ values by ANN-5, SVM-5 and MM-SVM-5 models during testing period at Khalkhal station.

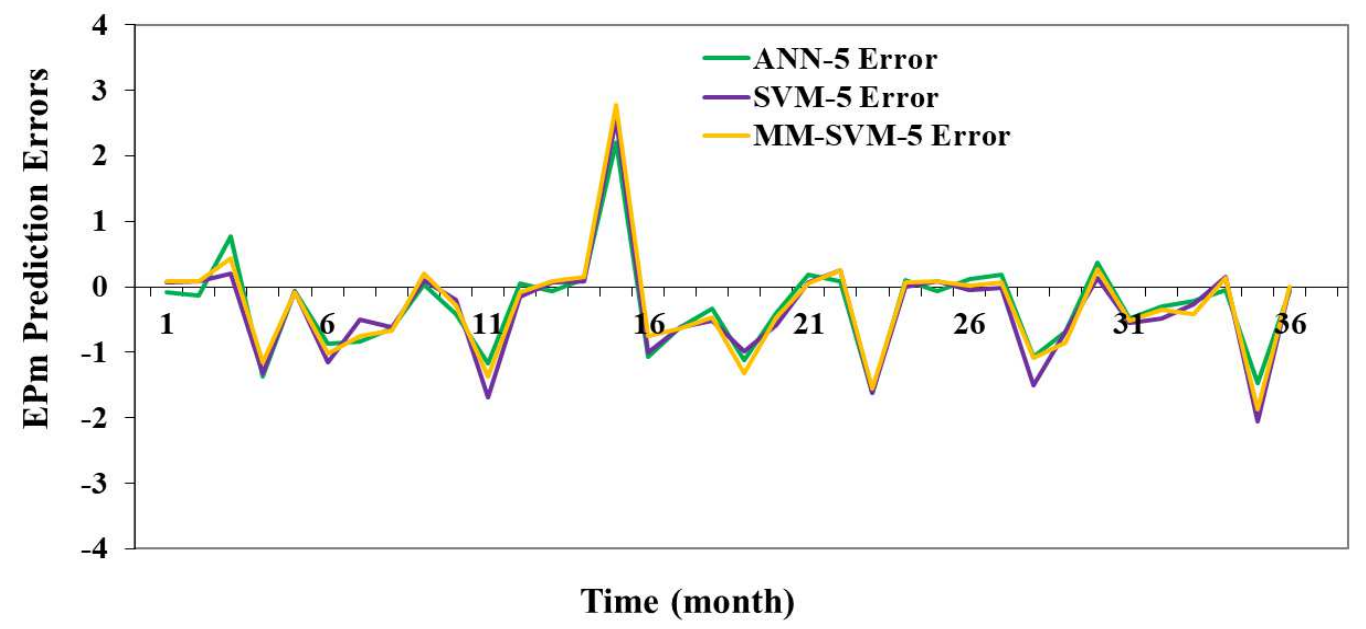

Fig. 10. $E P_{m}$ Prediction Errors plot by ANN-5, SVM-5 and MM-SVM-5 models during testing period at Khalkhal station.

\section{Conclusion}

Detection of the evaporation process that occurs in the hydrological cycle and under the influence of random phenomena is very complex. In this paper, the ability to predict $E P_{m}$ values with intelligent ANN and SVM models and by presenting multiple hybrid model (MM-SVM) in two meteorological stations of Ardabil and Khalkhal in Iran was evaluated. All possible hybrid scenarios were considered in determining the inputs of the ANN and SVM intelligent models to estimate $E P_{m}$. The outputs obtained from the models were evaluated and presented using numerical and visual performance evaluation criteria. In general, the results obtained in the present study can be classified and expressed as follows:

- In both Ardabil and Khalkhal stations, scenarios were selected as superior scenarios in which there were three and four input variables (i.e., $T, S, W$ and $R H$ ). In other words, the $E P_{m}$ process in the study area is very random and more climatic information is needed to achieve the desired result in predicting this process.

- At Ardabil station, the MM-SVM-6 model had better results compared to the two models ANN-7 and SVM-7. While ANN-5 model was selected as the best model in Khalkhal 
station. Given the actual mechanisms between the independent and dependent variables, it is natural for intelligent models to present different results in different regions.

- The SVM-7 model was able to act as the second top model after the MM-SVM-6 model at Ardabil station. While at Khalkhal station, the MM-SVM-5 model followed the results of the ANN-5 model as the second superior model. In general, all three forecasting models ANN, SVM and MM-SVM were able to show better results in Khalkhal station than Ardabil station in all scenarios and recorded less error in $E P_{m}$ forecasting.

- The proposed MM-SVM hybrid model for $E P_{m}$ prediction in specific study areas was able to increase the accuracy of predictions in scenarios with high correlation between its components and $E P_{m}$ by applying the strategy of multiple models with inputs predicted by independent models. So that the incremental, constant and decreasing modes in the accuracy of $E P_{m}$ prediction by this hybrid model under the above conditions (especially in Ardabil station) were quite clear.

- In general, the proposed hybrid intelligent model in the present study has a strong modeling strategy for estimating $E P_{m}$ values in a specific study area, especially in a specific station (i.e., Ardabil) and can be used in the discussion of engineering and management of water resources.

\section{Declarations}

Funding: Not applicable.

Conflict of interest: The authors declare no conflict of interest.

Availability of data and material: The data used were obtained from the Iran Meteorological Organization.

Code availability: Weka software user interface was used.

Authors' contributions: All authors have contributed to different sections of the article.

\section{References}

Ashrafzadeh A, Malik A, Jothiprakash V, Ghorbani MA, Biazar SM (2020) Estimation of daily pan evaporation using neural networks and meta-heuristic approaches ISH Journal of Hydraulic Engineering 26:421-429 
Aytek A, Guven A, Yuce MI, Aksoy H (2008) An explicit neural network formulation for evapotranspiration Hydrological sciences journal 53:893-904

Bhagat SK, Tung TM, Yaseen ZM (2020) Heavy metal contamination prediction using ensemble model: Case study of Bay sedimentation, Australia Journal of Hazardous Materials 403:123492

Bruton J, McClendon R, Hoogenboom G (2000) Estimating daily pan evaporation with artificial neural networks Transactions of the ASAE 43:491

Chen Q, Dai G, Liu H (2002) Volume of fluid model for turbulence numerical simulation of stepped spillway overflow Journal of Hydraulic Engineering 128:683-688

Ehteram M, Salih SQ, Yaseen ZM (2020) Efficiency evaluation of reverse osmosis desalination plant using hybridized multilayer perceptron with particle swarm optimization Environmental Science and Pollution Research:1-14

Eslamian S, Gohari S, Biabanaki M, Malekian R (2008) Estimation of monthly pan evaporation using artificial neural networks and support vector machines J Appl Sci 8:3497-3502

Garner SR Weka: The waikato environment for knowledge analysis. In: Proceedings of the New Zealand computer science research students conference, 1995. pp 57-64

Ghaemi A, Rezaie-Balf M, Adamowski J, Kisi O, Quilty J (2019) On the applicability of maximum overlap discrete wavelet transform integrated with MARS and M5 model tree for monthly pan evaporation prediction Agricultural and Forest Meteorology 278:107647

Ghorbani M, Deo RC, Yaseen ZM, Kashani MH, Mohammadi B (2018a) Pan evaporation prediction using a hybrid multilayer perceptron-firefly algorithm (MLP-FFA) model: case study in North Iran Theoretical and applied climatology 133:1119-1131

Ghorbani M, Khatibi R, Hosseini B, Bilgili M (2013) Relative importance of parameters affecting wind speed prediction using artificial neural networks theoretical and applied climatology 114:107-114

Ghorbani M, Khatibi R, Karimi V, Yaseen ZM, Zounemat-Kermani M (2018b) Learning from multiple models using artificial intelligence to improve model prediction accuracies: application to river flows Water resources management 32:4201-4215

Gupta HV, Kling H, Yilmaz KK, Martinez GF (2009) Decomposition of the mean squared error and NSE performance criteria: Implications for improving hydrological modelling Journal of hydrology 377:80-91

Jing W et al. (2019) Implementation of evolutionary computing models for reference evapotranspiration modeling: short review, assessment and possible future research directions Engineering applications of computational fluid mechanics 13:811-823

Kashani MH, Ghorbani MA, Shahabi M, Naganna SR, Diop L (2020) Multiple AI model integration strategy - application to saturated hydraulic conductivity prediction from easily available soil properties Soil and Tillage Research 196:104449

Khatibi R, Ghorbani MA, Jani R, Servati M (2018) Soil cation exchange capacity predicted by learning from multiple modelling: Forming multiple models run by SVM to Learn from ANN and its hybrid with firefly algorithm. In: Handbook of research on predictive modeling and optimization methods in science and engineering. IGI Global, pp 465-480

Khatibi R, Ghorbani MA, Pourhosseini FA (2017) Stream flow predictions using nature-inspired firefly algorithms and a multiple model strategy-directions of innovation towards next generation practices Advanced Engineering Informatics 34:80-89 
Khosravi K et al. (2019) Meteorological data mining and hybrid data-intelligence models for reference evaporation simulation: A case study in Iraq Computers and Electronics in Agriculture 167:105041

Kisi O (2015) Pan evaporation modeling using least square support vector machine, multivariate adaptive regression splines and M5 model tree Journal of Hydrology 528:312-320

Kişi Ö (2006) Daily pan evaporation modelling using a neuro-fuzzy computing technique Journal of hydrology 329:636-646

Kisi O, Genc O, Dinc S, Zounemat-Kermani M (2016) Daily pan evaporation modeling using chisquared automatic interaction detector, neural networks, classification and regression tree Computers and Electronics in Agriculture 122:112-117

Maier HR, Dandy GC (2000) Neural networks for the prediction and forecasting of water resources variables: a review of modelling issues and applications Environmental modelling \& software 15:101-124

Malik A, Kumar A, Ghorbani MA, Kashani MH, Kisi O, Kim S (2019) The viability of co-active fuzzy inference system model for monthly reference evapotranspiration estimation: case study of Uttarakhand State Hydrology Research 50:1623-1644

Malik A et al. (2020a) Modeling monthly pan evaporation process over the Indian central Himalayas: application of multiple learning artificial intelligence model Engineering Applications of Computational Fluid Mechanics 14:323-338

Malik A et al. (2020b) Pan Evaporation Estimation in Uttarakhand and Uttar Pradesh States, India: Validity of an Integrative Data Intelligence Model Atmosphere 11:553

Mantero P, Moser G, Serpico SB (2005) Partially supervised classification of remote sensing images through SVM-based probability density estimation IEEE Transactions on Geoscience and Remote Sensing 43:559-570

Naganna SR, Deka PC, Ghorbani MA, Biazar SM, Al-Ansari N, Yaseen ZM (2019) Dew point temperature estimation: application of artificial intelligence model integrated with natureinspired optimization algorithms Water 11:742

Piri J, Amin S, Moghaddamnia A, Keshavarz A, Han D, Remesan R (2009) Daily pan evaporation modeling in a hot and dry climate Journal of Hydrologic Engineering 14:803-811

Qasem SN, Samadianfard S, Kheshtgar S, Jarhan S, Kisi O, Shamshirband S, Chau K-W (2019) Modeling monthly pan evaporation using wavelet support vector regression and wavelet artificial neural networks in arid and humid climates Engineering Applications of Computational Fluid Mechanics 13:177-187

Rahimikhoob A (2009) Estimating daily pan evaporation using artificial neural network in a semiarid environment Theoretical and applied climatology 98:101-105

Rosenblatt F (1958) The perceptron: a probabilistic model for information storage and organization in the brain Psychological review 65:386

Seifi A, Soroush F (2020) Pan evaporation estimation and derivation of explicit optimized equations by novel hybrid meta-heuristic ANN based methods in different climates of Iran Computers and Electronics in Agriculture 173:105418

Shin K-S, Lee TS, Kim H-j (2005) An application of support vector machines in bankruptcy prediction model Expert systems with applications 28:127-135

Sudheer KP, Gosain AK, Mohana Rangan D, Saheb SM (2002) Modelling evaporation using an artificial neural network algorithm Hydrological Processes 16:3189-3202 doi:https://doi.org/10.1002/hyp.1096 
Tabari H, Marofi S, Sabziparvar A-A (2010) Estimation of daily pan evaporation using artificial neural network and multivariate non-linear regression Irrigation Science 28:399-406

Tao H, Keshtegar B, Yaseen ZM (2019) The Feasibility of Integrative Radial Basis M5Tree Predictive Model for River Suspended Sediment Load Simulation Water Resources Management 33:4471-4490

Tung TM, Yaseen ZM (2020) A survey on river water quality modelling using artificial intelligence models: 2000-2020 Journal of Hydrology 585:124670

Vapnik VN (1995) The nature of statistical learning Theory

Yaseen ZM et al. (2020) Prediction of evaporation in arid and semi-arid regions: a comparative study using different machine learning models Engineering applications of computational fluid mechanics 14:70-89

Yaseen ZM, Sulaiman SO, Deo RC, Chau K-W (2019) An enhanced extreme learning machine model for river flow forecasting: State-of-the-art, practical applications in water resource engineering area and future research direction Journal of Hydrology 569:387-408 
Figures

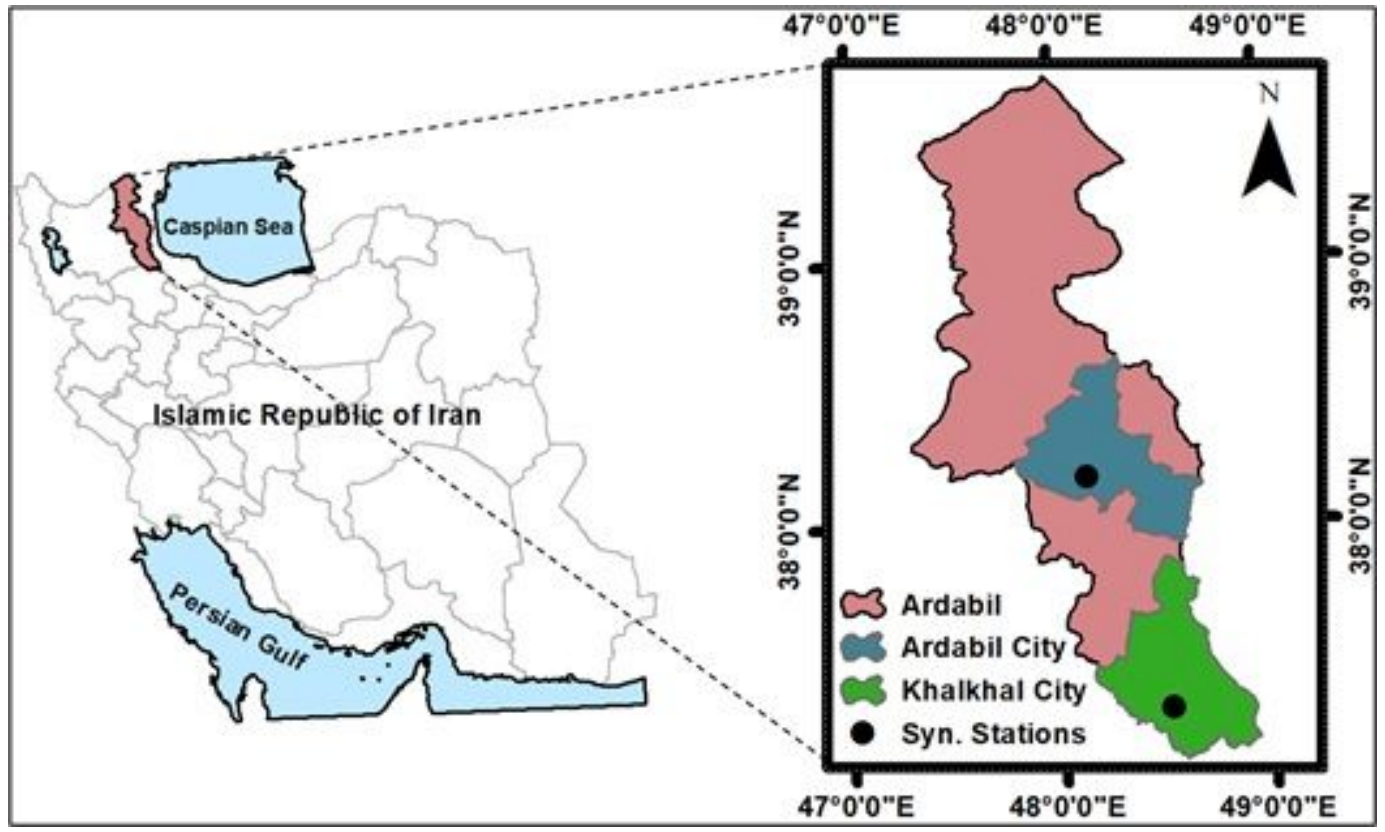

Figure 1

Geographic location of the Ardabil and Khalkhal meteorological stations.
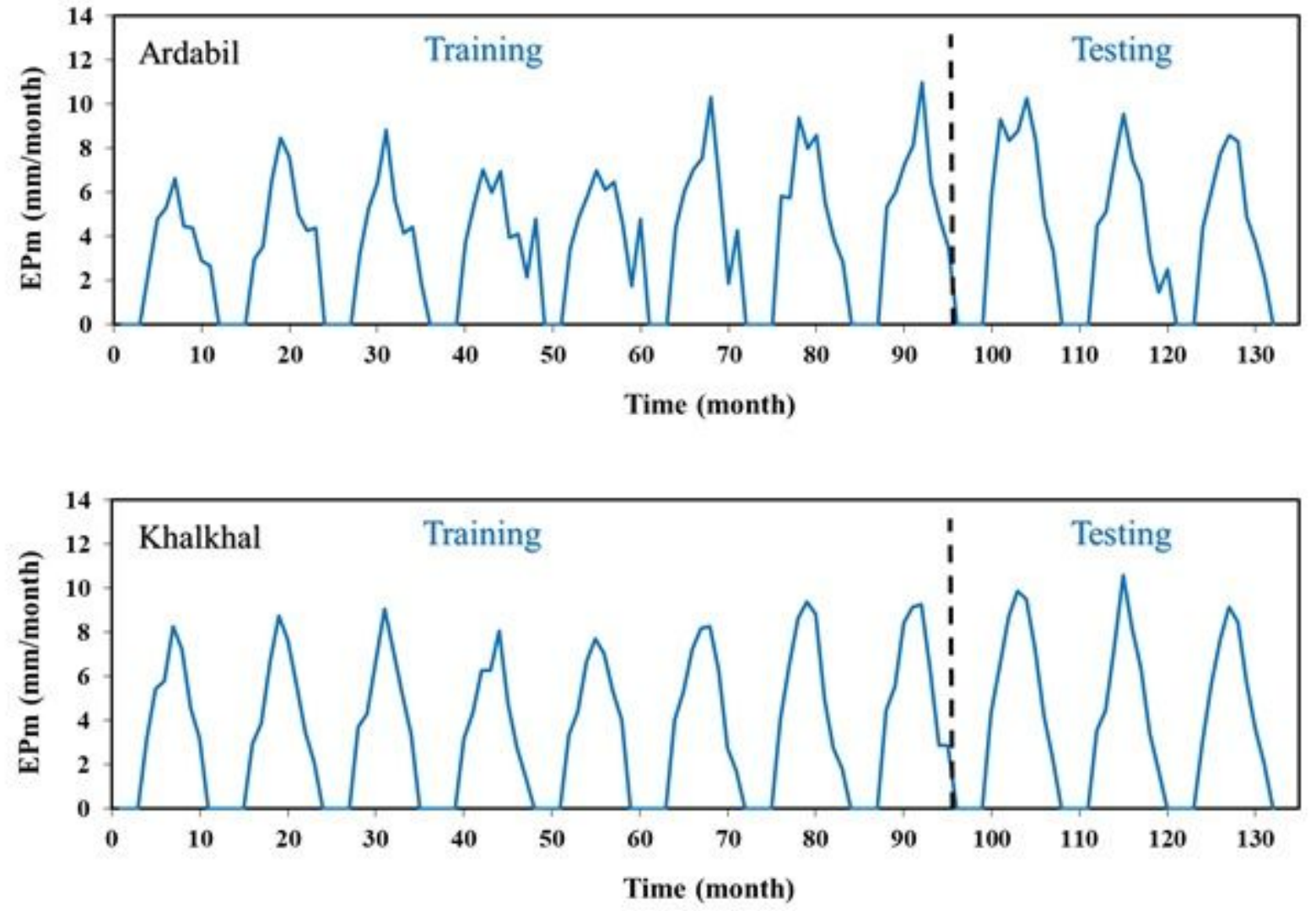

Figure 2 
Variation of the EPm time-series for the period 2009-2019 depicting the training and testing datasets in Ardabil and Khalkhal meteorological stations.
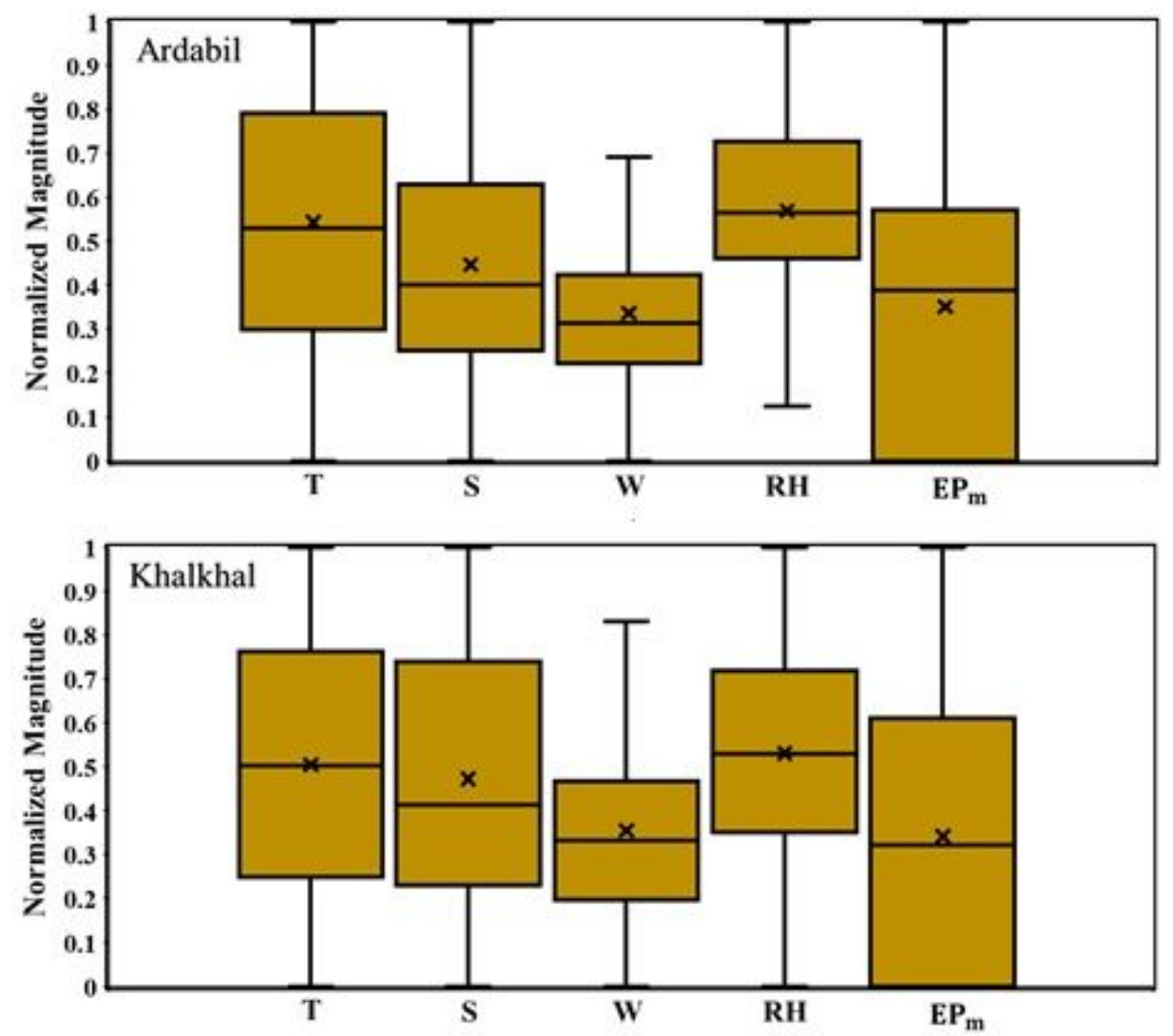

Figure 3

Boxplot of Normalized Predictor and Objective variables.

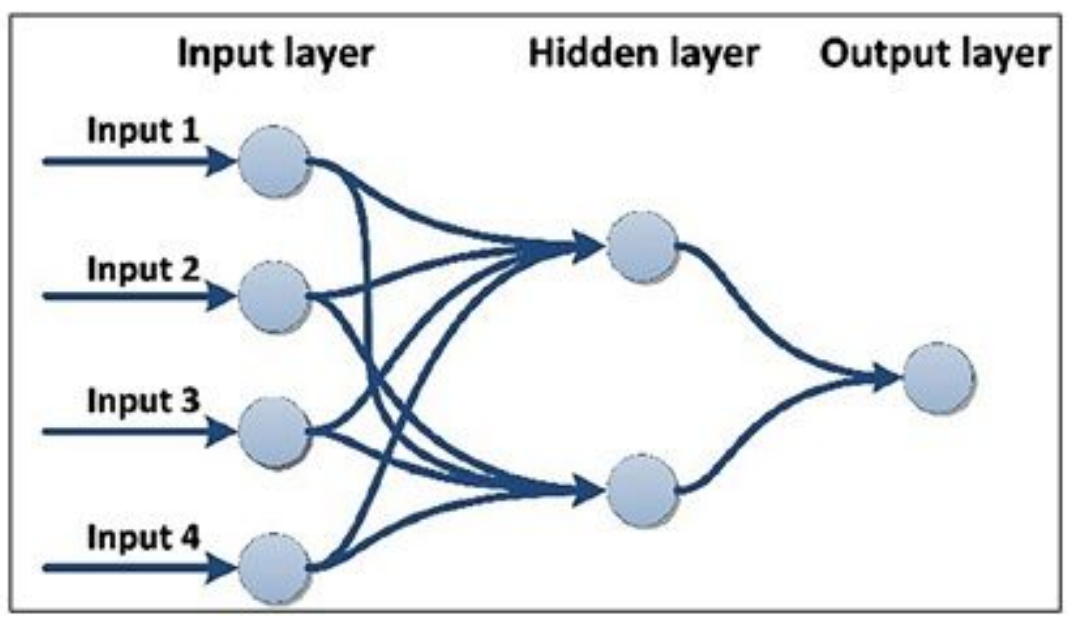

Figure 4

General structure of an artificial neural network (ANN). 


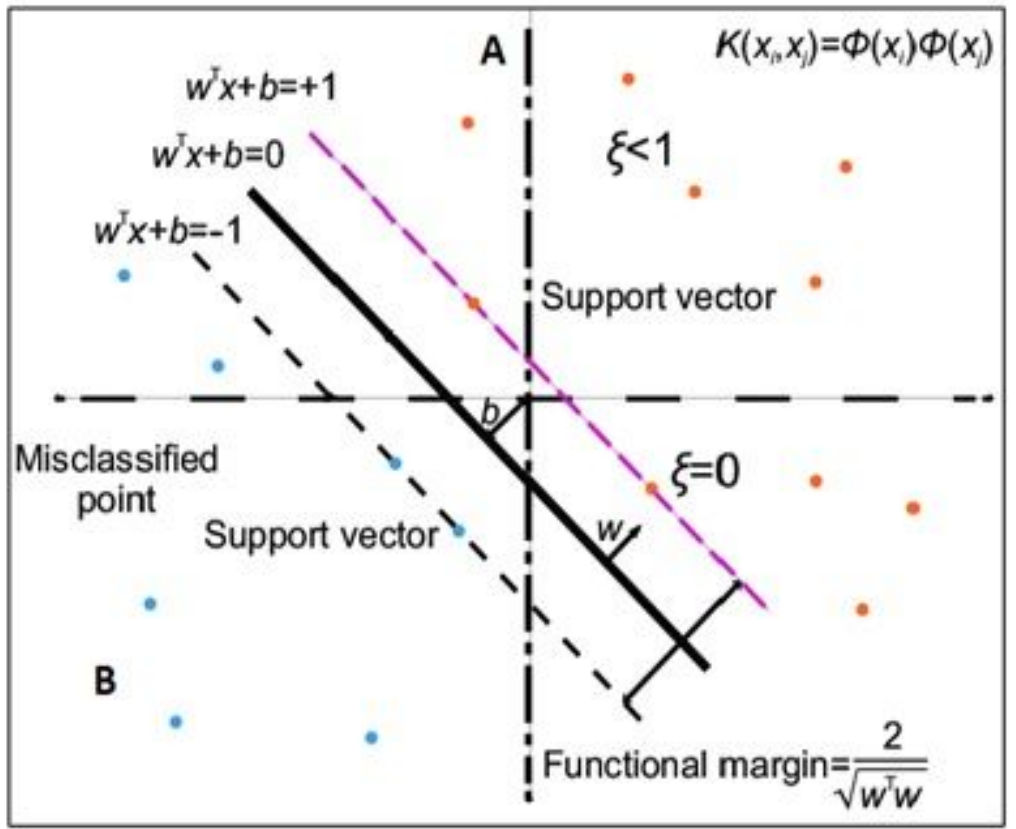

Figure 5

Graphic display of Support vectors.

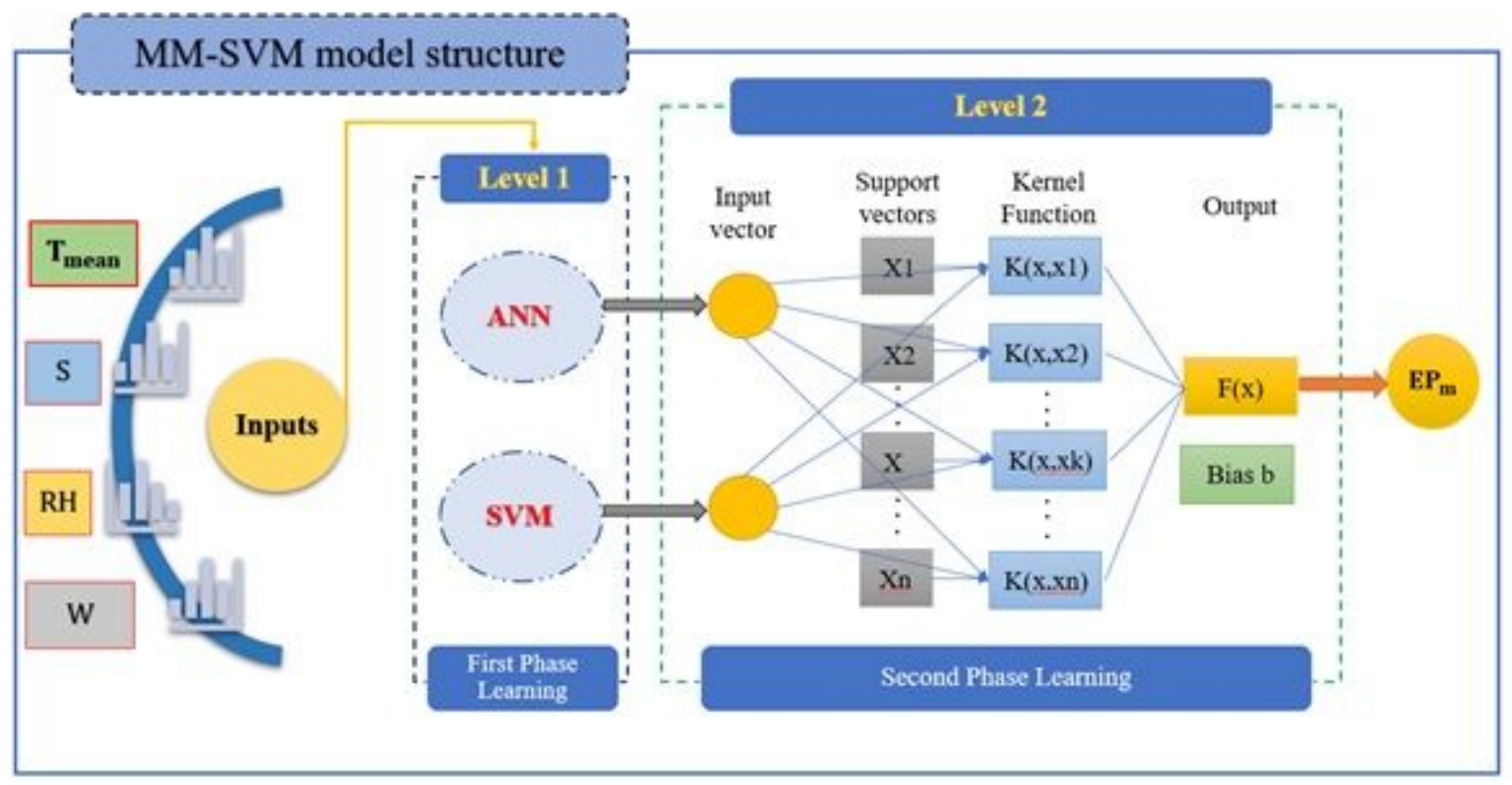

Figure 6

Overall structure of the MM-SVM model. 


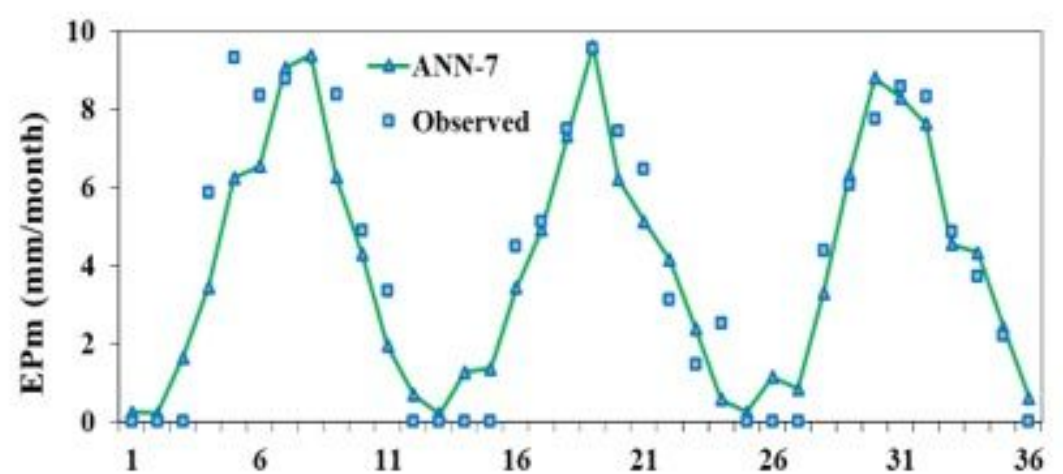

Time (month)
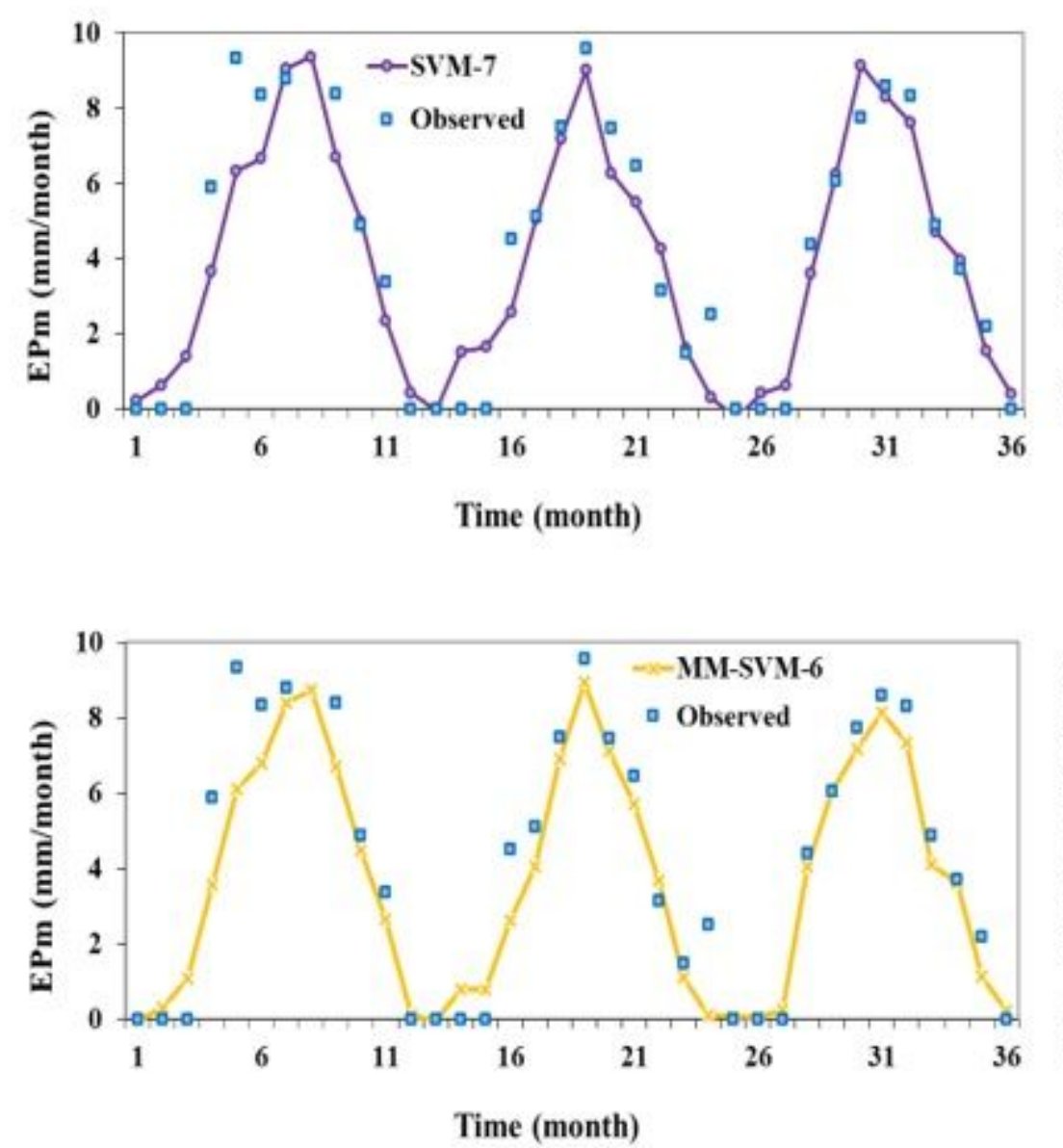
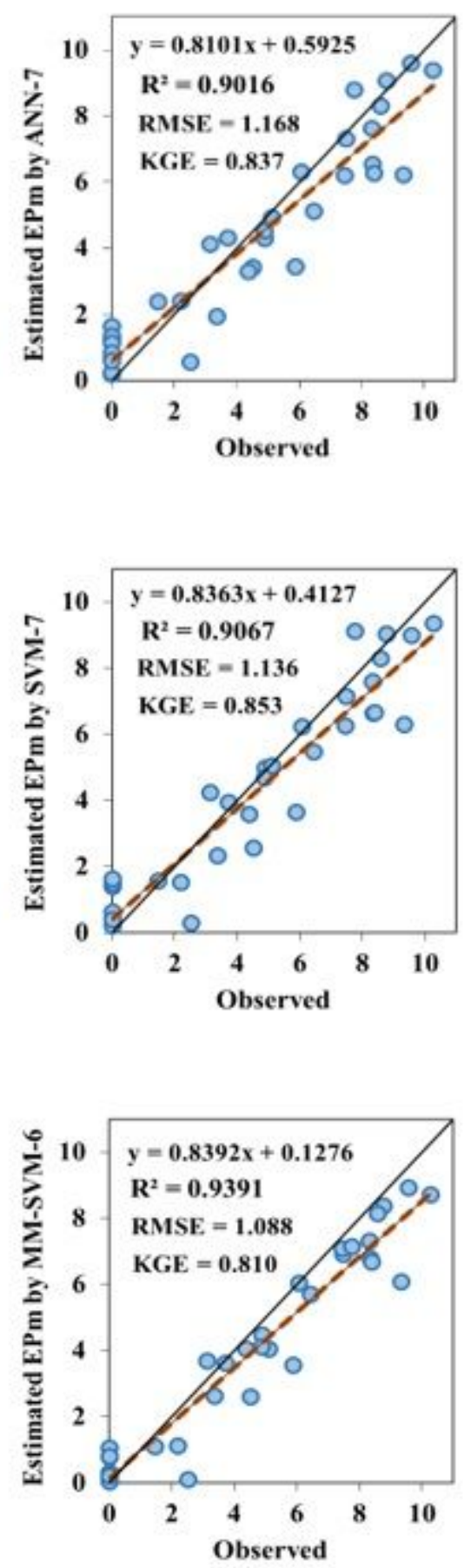

Figure 7

Time series (left) and scatter (right) plots between observed and simulated EPm values by ANN-7, SVM-7 and MM-SVM-6 models during testing period at Ardabil station. 


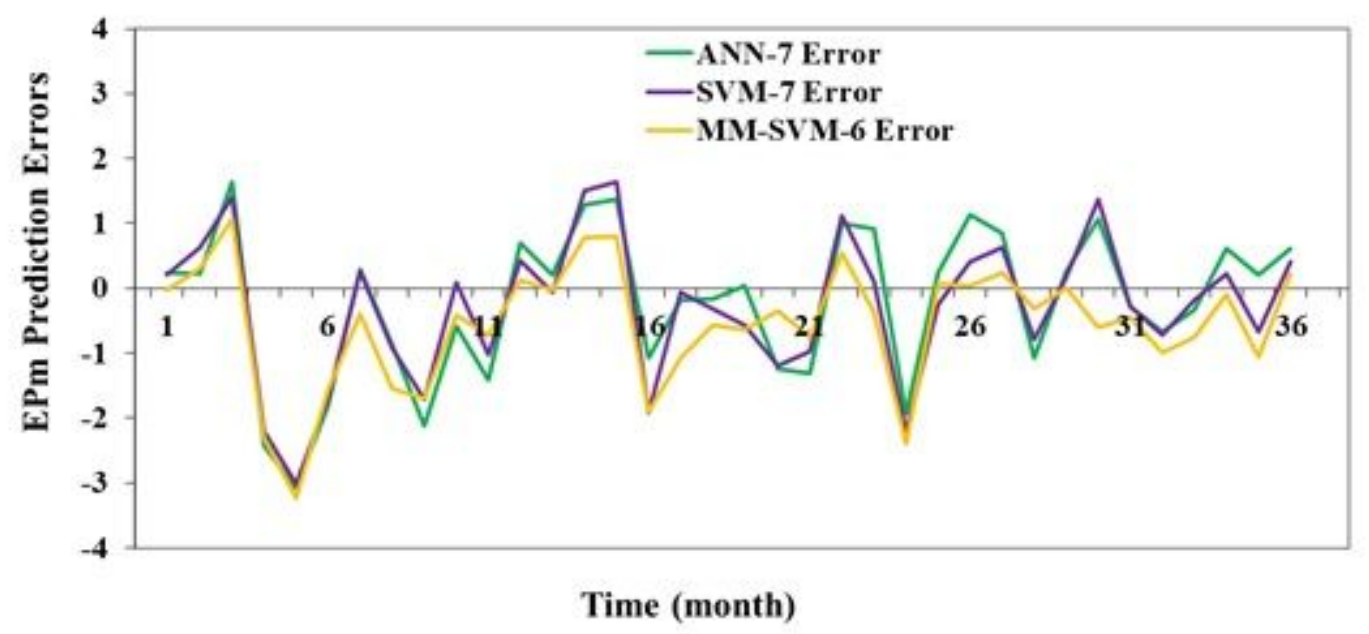

Figure 8

EPm Prediction Errors plot by ANN-7, SVM-7 and MM-SVM-6 models during testing period at Ardabil station. 

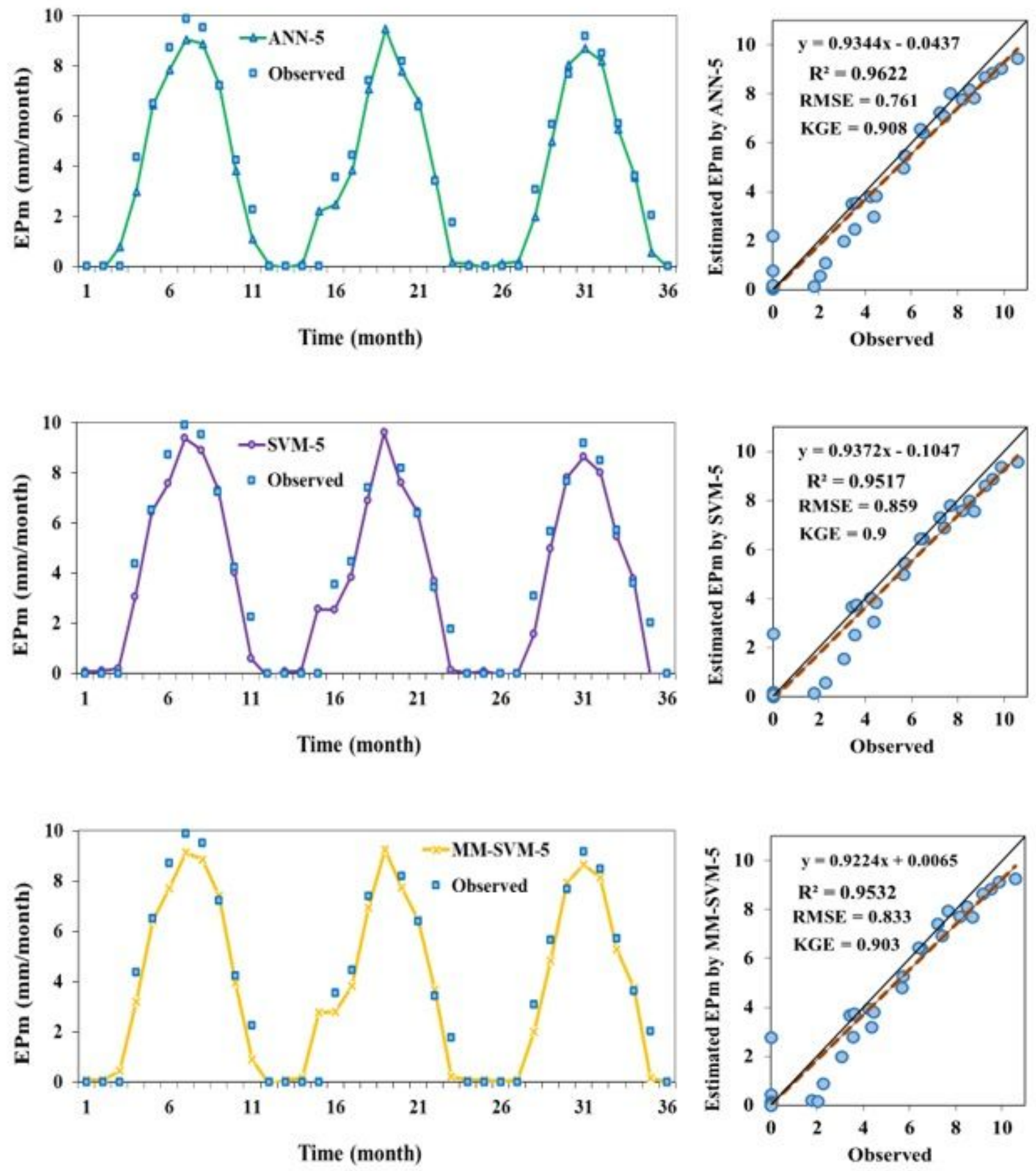

Figure 9

Time series (left) and scatter (right) plots between observed and simulated EPm values by ANN-5, SVM-5 and MM-SVM-5 models during testing period at Khalkhal station. 


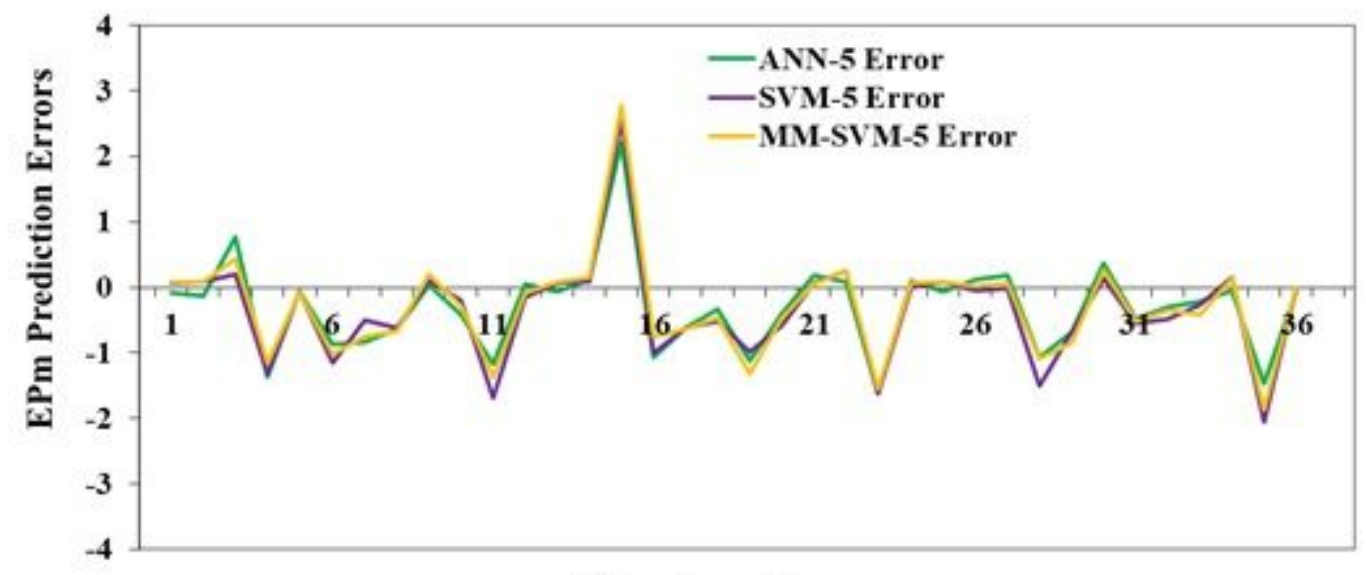

Time (month)

Figure 10

EPm Prediction Errors plot by ANN-5, SVM-5 and MM-SVM-5 models during testing period at Khalkhal station. 